\title{
Micromechanical Behavior of Single-Crystal Superalloy with Different Crystal Orientations by Microindentation
}

\author{
Jinghui Li, ${ }^{1}$ Fuguo Li, ${ }^{1}$ Junzhe Dong, ${ }^{1}$ Zhanwei Yuan, $^{2}$ and Shuo Zhang ${ }^{3}$ \\ ${ }^{1}$ State Key Laboratory of Solidification Processing, School of Materials Science and Engineering, Northwestern Polytechnical University, \\ Xian 710072, China \\ ${ }^{2}$ School of Materials Science and Engineering, Chang'an University, Xian 710061, China \\ ${ }^{3}$ School of Materials Science and Engineering, Tsinghua University, Beijing 100062, China
}

Correspondence should be addressed to Fuguo Li; 1037832244@qq.com

Received 2 September 2014; Accepted 5 January 2015

Academic Editor: Sheng-Rui Jian

Copyright (C) 2015 Jinghui Li et al. This is an open access article distributed under the Creative Commons Attribution License, which permits unrestricted use, distribution, and reproduction in any medium, provided the original work is properly cited.

In order to investigate the anisotropic micromechanical properties of single-crystal nickel-based superalloy DD99 of four crystallographic orientations, (001), (215), (405), and (605), microindentation test (MIT) was conducted with different loads and loading velocities by a sharp Berkovich indenter. Some material parameters reflecting the micromechanical behavior of DD99, such as microhardness $H$, Young's modulus $E$, yield stress $\sigma_{y}$, strain hardening component $n$, and tensile strength $\sigma_{b}$, can be obtained from load-displacement relations. $H$ and $E$ of four different crystal planes evidently decrease with the increase of $h$. The reduction of $H$ is due to dislocation hardening while $E$ is related to interplanar spacing and crystal variable. $\sigma_{y}$ of (215) is the largest among four crystal planes, followed by (605), and (001) has the lowest value. $n$ of (215) is the lowest, followed by (605), and that of (001) is the largest. Subsequently, a simplified elastic-plastic material model was employed for 3D microindentation simulation of DD99 with various crystal orientations. The simulation results agreed well with experimental, which confirmed the accuracy of the simplified material model.

\section{Introduction}

In recent years, single-crystal nickel-based superalloys are widely used as blade of modern gas turbine aeroengines, as they significantly raise the operation temperature and efficiency due to excellent mechanical properties in service [1-6]. Their excellent high-temperature properties are superior to conventional cast alloys, such as high-temperature creep and oxidation-resistant performance, which results from the elimination of grain boundaries in single-crystal alloys. However, the absence of grain boundaries also leads to orientation-dependent material response [7-9]. To date, a lot of researches concerned about different orientation of single-crystal nickelbased superalloys have been done. Caron et al. [10] investigated the anisotropic creep behavior of some advanced superalloys (CMSX-2, Alloy 454, MXON, and CMSX-4) in the temperature ranging from 1033 to $1323 \mathrm{~K}$. He et al. [11] discussed the creep/fatigue damage characteristics of DD6 and the results show the capability of DD6 to avoid fatigue damage in [011] direction is better than that in [001] direction. Yi et al. [12] gave modeling process of tertiary creep of singlecrystal superalloy along different orientations. Wu et al. [13] made extensile and compression tests at different temperatures on DD8 with various strain rates and the results indicate that the tendency to the plastic deformation inhomogeneity decreases in the order of [011], [001], and [111]. The previous investigations mainly concentrated on the fatigue life and creep properties with different orientations, while other fundamental performances of materials, such as hardness, Young's modulus, and yield stress are rarely focused on.

Conventional tensile tests are difficult to conduct at nano-and microscales to determine orientation dependent behavior. Microindentation can be an alternative approach to tension or compression to probe the micromechanical properties, such as elastic modulus and hardness. Due to its precise measurement and advantages of celerity, accuracy, 


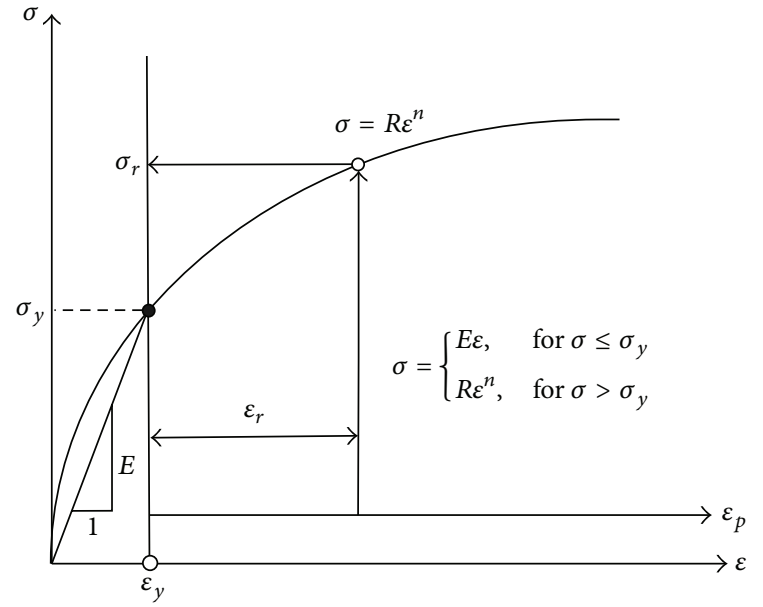

FIgUre 1: Power-law elastic-plastic, true stress-strain behavior [14].

and nondestructiveness [15], it will become increasingly popular in the future. However, thorough understanding of materials behavior under indenter cannot be achieved just through MIT; for example, the equivalent stress and strain cannot be obtained directly by indentation.

FEM may be used as a supplement to solve complex $3 \mathrm{D}$ problems and more information can be extracted from microindentation simulation [16-18]. Lim and Munawar Chaudhri [19] investigated microindentation hardness of individual grains [(110) and (111) surfaces] of a polycrystalline copper using a spherical indenter and reported the indentation hardness in copper with different orientations to be very similar. Liu et al. [20] performed nanoindentation simulation using 3D elastic-plastic crystal plasticity FEM on singlecrystal copper specimens on three orientations [(011), (100), and (111)] using a conical indenter and reported twofold, fourfold, and sixfold symmetries on (011), (100), and (111) faces, respectively. Fivel et al. [21] developed a 3D model to combine discrete dislocations with FEM for nanoindentation simulation on single-crystal copper. However, most of these researches were based on material properties of single-crystal data obtained from tensile testing at macroscale. In fact, it is essential to extract these parameters at micrometer scale.

In this paper, MIT were conducted on crystal planes of nickel-based single-crystal DD99 to investigate its micromechanical properties. Subsequently, a FEM model based on the results of MIT was implemented in 3D ABAQUS/Explicit to prove the accuracy of this FEM model.

\section{Calculation Methods}

2.1. Elastic-Plastic Properties. The load-displacement response obtained by microindentation contains information about the elastic and plastic deformation of the indented materials. Therefore, it is often regarded as "fingerprint" of materials' properties under identification [22]. Mechanical properties, such as the hardness and Young's modulus, can be readily extracted from the load-displacement curves. In general,

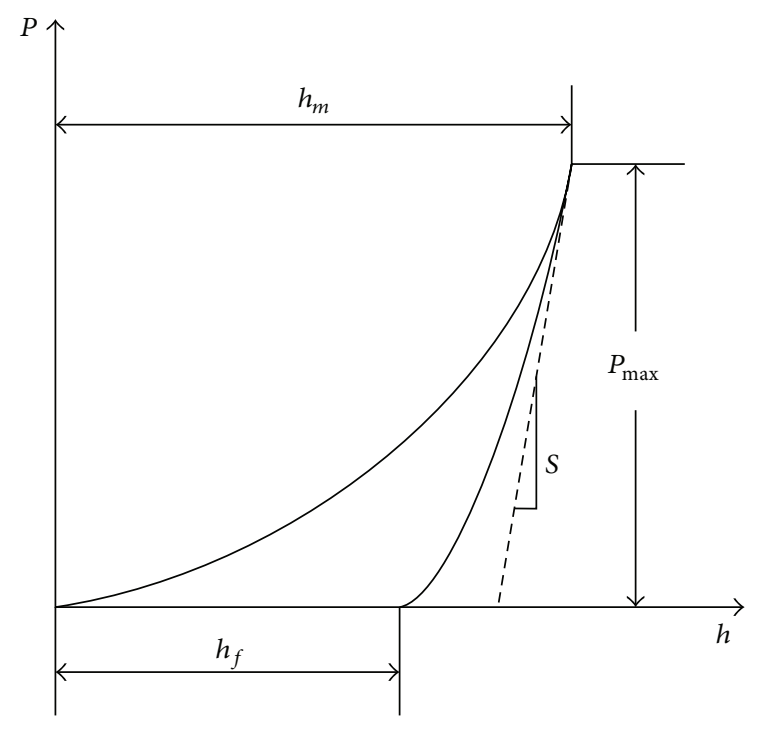

FIgURE 2: The typical $P$ - $h$ curve in instrumented indentation test.

plastic behavior of metals can be characterized by a powerlaw description, as shown in Figure 1. A simplified elasticplastic, true stress-strain behavior can be expressed as

$$
\sigma= \begin{cases}E \varepsilon, & \text { for } \sigma \leq \sigma_{y} \\ R \varepsilon^{n}, & \text { for } \sigma \geq \sigma_{y} .\end{cases}
$$

When $\sigma$ is equal to $\sigma_{y}, R$ can be deduced as follows:

$$
R=\sigma_{y}\left(\frac{E}{\sigma_{y}}\right)^{n} .
$$

Thus, (1) can be rewritten as follows:

$$
\sigma= \begin{cases}E \varepsilon, & \text { for } \sigma \leq \sigma_{y} \\ \sigma_{y}\left(1+\frac{E}{\sigma_{y}} \varepsilon_{r}\right)^{n}, & \text { for } \sigma \geq \sigma_{y} .\end{cases}
$$

In order to describe the mechanical properties of a powerlaw material, Young's modulus $E$, yield stress $\sigma_{y}$, and strain hardening exponent $n$ are needed.

The typical $P$ - $h$ curve of microindentation test is shown in Figure 2. Two important parameters (maximum indentation depth $h_{m}$ and maximum load $P_{m}$ ) can be obtained from the curve. According to Kick's law, the loading curve of indentation can be expressed as

$$
P=C h^{2} \text {. }
$$

According to the model proposed by Oliver and Pharr $[23,24]$, unloading curve can be interpreted as

$$
P=B \times\left(h-h_{f}\right)^{t} .
$$

The relationship between the apparent modulus $E^{*}$ and Young's modulus $E$ is as follows:

$$
\frac{1}{E^{*}}=\frac{1-v^{2}}{E}+\frac{1-v_{i}^{2}}{E_{i}}
$$


$E_{i}$ and $v_{i}$ are Young's modulus and Poisson's ratio of the indenter whose values are $1141 \mathrm{GPa}$ and 0.07 for diamond indenter, respectively [25].

According to King [26], $E^{*}$ has the form

$$
E^{*}=\frac{\sqrt{\pi}}{2 \beta} \frac{S}{Q}
$$

$S$ and $Q$ can be obtained by the following equations, respectively:

$$
\begin{gathered}
S=\left.\frac{d P}{d h}\right|_{h=h_{m}}=m \times B\left(h_{m}-h_{f}\right)^{m-1}, \\
Q=\pi\left(h_{m}-\gamma \frac{P_{m}}{S}\right)^{2} \tan ^{2} \theta=K\left(h_{m}-\gamma \frac{P_{m}}{S}\right)^{2},
\end{gathered}
$$

where $K$ is a constant related with indenter, whose value is 24.56 for Berkovich indenter, and $\gamma$ is a coefficient with value of 0.75 for Berkovich indenter [27, 28].

The next task is to find the yield stress $\sigma_{y}$ and strain hardening exponent $n$. The method used to obtain $\sigma_{y}$ and $n$ is dimensional analysis proposed by Y. T. Cheng and C. M. Cheng and Tunvisut et al. [29-33]. For a sharp indenter (Berkovich indenter in this paper), the load $P$ can be related with the following parameters [34]:

$$
P=P\left(h, E^{*}, \sigma_{c}, n\right) .
$$

According to $\Pi$ theorem in dimensional analysis, the equation above can be rewritten as

$$
P=\sigma_{c} h^{2} \Pi_{1}\left(\frac{E^{*}}{\sigma_{c}}, n\right) .
$$

$\Pi_{1}$ function is independent of $n$ when strain is equal to 0.033 [34]. And $\sigma_{0.033}$ can be obtained as

$$
\begin{aligned}
\Pi_{1}\left(\frac{E^{*}}{\sigma_{0.033}}\right)= & \frac{C}{\sigma_{0.033}} \\
= & -1.131\left[\ln \left(\frac{E^{*}}{\sigma_{0.033}}\right)\right]^{3} \\
& +13.635\left[\ln \left(\frac{E^{*}}{\sigma_{0.033}}\right)\right]^{2} \\
& -30.594\left[\ln \left(\frac{E^{*}}{\sigma_{0.033}}\right)\right]+29.267 .
\end{aligned}
$$

Similarly, the unloading slope can be described as follows at $h=h_{m}$ :

$$
\left.\frac{d P_{u}}{d h}\right|_{h=h_{m}}=S=E^{*} h_{m} \Pi_{2}\left(\frac{E^{*}}{\sigma_{c}}, n\right)
$$

$$
\begin{aligned}
\Pi_{2}\left(\frac{E^{*}}{\sigma_{c}}, n\right) \\
=\frac{S}{E^{*} h_{m}} \\
=\left(-1.40557 n^{3}+0.77526 n^{2}+0.1583 n-0.06831\right) \\
\quad \cdot\left[\ln \left(\frac{E^{*}}{\sigma_{0.033}}\right)\right]^{3} \\
+\left(17.93006 n^{3}-9.22091 n^{2}-2.37733 n+0.86295\right) \\
\cdot\left[\ln \left(\frac{E^{*}}{\sigma_{0.033}}\right)\right]^{2} \\
+\left(-79.99715 n^{3}+40.5562 n^{2}+9.00157 n-2.54543\right) \\
\cdot\left[\ln \left(\frac{E^{*}}{\sigma_{0.033}}\right)\right] \\
+\left(122.65069 n^{3}-63.88418 n^{2}-9.58936 n+6.20045\right) .
\end{aligned}
$$

Finally, after plugging value of $\sigma_{0.033}$ and $n$ into (3), $\sigma_{y}$ can be calculated. Thus, one can obtain the elastic-plastic model characterized by a power-law function based on (1) and (2).

2.2. Tensile Strength. The ultimate tensile strength characterizes the resistance of largest uniform plastic deformation. The tensile strength is usually determined by uniaxial tensile test: the highest point of the stress-strain curve is the tensile strength. However, it can also be calculated by MIT.

In the stage of uniform plastic deformation stage, load $F$ is as follows:

$$
F=\sigma A .
$$

The result of differential calculation of (15) is

$$
\frac{d F}{F}=\frac{d \bar{\sigma}}{\bar{\sigma}}+\frac{d A}{A} .
$$

When nonuniform deformation such as necking occurs on certain part of materials, $F$ reaches its maximum value and $d F=0$. According to (16), it can be induced that

$$
\begin{gathered}
\frac{d \bar{\sigma}}{\bar{\sigma}}=-\frac{d A}{A}=d \varepsilon, \\
\frac{d \bar{\sigma}}{d \varepsilon}=\bar{\sigma} .
\end{gathered}
$$

It has the following relationship, according to (18):

$$
\left.\frac{d \sigma}{d \varepsilon}\right|_{\varepsilon=\varepsilon_{b}}=\left.\bar{\sigma}\right|_{\varepsilon=\varepsilon_{b}} .
$$

According to (19), $\varepsilon_{b}$ can be calculated and it is equal to $n$, which has been confirmed by [35]. Consider

$$
\begin{gathered}
F=\sigma_{b} A=\bar{\sigma}_{b} A_{b}=\left(R \varepsilon_{b}^{n}\right) A_{b}=\left(R n^{n}\right) A_{b}, \\
\sigma_{b}=\left(R n^{n}\right) \frac{A_{b}}{A} .
\end{gathered}
$$


TABLE 1: Chemical composition of DD99 superalloy (mass fraction, $\%)$.

\begin{tabular}{lrrrrrrr}
\hline C & Cr & Co & W & $\mathrm{Al}$ & $\mathrm{Ti}$ & $\mathrm{Ta}$ & $\mathrm{Ni}$ \\
\hline 0.016 & 8.5 & 5.0 & 9.5 & 5.5 & 2.2 & 2.8 & $\mathrm{Bal}$. \\
\hline
\end{tabular}

Its formula is

$$
\ln \frac{A}{A_{b}}=\varepsilon_{b} .
$$

According to (21) and (22), $\sigma_{b}$ can be calculated:

$$
\sigma_{b}=\left(R n^{n}\right) e^{-\varepsilon_{b}}=\left(R n^{n}\right) e^{-n}=R\left(\frac{n}{e}\right)^{n} .
$$

2.3. Microhardness. Hardness is an ability of resistance to permanent (plastic) deformation. It represents the overall mechanical properties of materials. For example, hardness is related to other mechanics parameters, such as Young's modulus, yield stress, and strain hardening component [36]. Besides, many references have shown that the intrinsic material length scale characterizing size scale can be identified from microhardness [37-41]. It has been found that the microhardness of materials is significantly higher that the microhardness and, furthermore, the correlation of microhardness and the indentation depth implies that the materials strength depends on both the absolute specimen size and strain gradients. Therefore, the results of the microhardness provide a new implication for the strain gradientdependent constitutive equations in continuum plasticity theory. This has led to the development of phenomenological or mechanism-based strain gradient plasticity (SGP) theories, which have been used to interpret the size dependence of hardness from the micro- to nanoscales.

Shim et al. [42] guessed the yield strength very roughly based on the hardness values from Berkovich indentations. Nix and Gao [43] showed that equivalent stress $\left(\sigma_{\text {eq }}\right)$ has the following relationship with hardness: $\sigma_{\mathrm{eq}}=H / 3$. As a testing method under micro- and nanoscale, MIT plays an important role in the evaluation of microhardness and the microhardness can be obtained as follows:

$$
H=\frac{P_{m}}{Q}=\frac{P_{m}}{\pi\left(h_{m}-\gamma\left(P_{m} / S\right)\right)^{2} \tan ^{2} \theta} .
$$

\section{Experimental and Simulation Procedures}

3.1. Experimental Procedure. The nominal chemical compositions of as-received single-crystal nickel-based superalloy DD99 ( $5 \mathrm{~mm} \times 5 \mathrm{~mm} \times 3 \mathrm{~mm}$ rectangle block) which has its crystal plane (001) marked in advance are shown in Table 1.

Although nickel-based single crystal has the optimum performance along crystal orientation [001] [14], there inevitably exist misorientations for actual engineering application. Moreover, as the structures of production, such as blade parts of aeroengine, are complicated, it is difficult to guarantee each plane of the product is parallel to [001]. In order to investigate the orientation dependent properties and provide performance reference of different planes for engineering applications in the future, the specimens of DD99 were subjected to wire-electrode cutting with angle of $30^{\circ}, 45^{\circ}$, and $60^{\circ}$ to crystal plane (001), as shown in Figures 3(a), 3(b), and 3(c). The red lines in Figure 3 represent molybdenum wire used in wire-electrode cutting and the cutting curve is parallel to [010].

The cutting specimens along with the original one with crystal plane (001) were carefully ground with sand paper. Then, they were polished with $1.5 \mu \mathrm{m}$ diamond to mirror finish. Subsequently, the specimens were etched with corrosives $\left(5 \mathrm{~g} \mathrm{CuSO}_{4}+20 \mathrm{~mL} \mathrm{HCl}+100 \mathrm{~mL} \mathrm{H} \mathrm{H}_{2} \mathrm{O}\right)$ for $15 \mathrm{~s}$ to reduce the influence of surface hardening. Finally, MIT was performed using the commercial MCT W501 equipped with a Berkovich diamond indenter at room temperature. The test condition was shown in Table 2. There are four different loading velocities and under each of them nine different maximum loads were conducted. Notably, each test was conducted five times and the average values were calculated in order to eliminate the errors.

3.2. Simulation Procedure. In the researches of Li et al. [44] and Yuan et al. [45], the axisymmetric 2D was created by using the quadrilateral elements to simulate the indentation process and the $P$ - $h$ line of FEM is slightly higher than that of experiments. Walter and Mitterer [46] found that 2D model predicts higher scatter and relatively higher mean Young's modulus compared to 3D model. According to researches from FEM simulation of indentation, it can be concluded that the main differences between $2 \mathrm{D}$ and $3 \mathrm{D}$ model are in the following two aspects.

In terms of the shape of indenter, the Berkovich indenter of $2 \mathrm{D}$ model is represented by a straight with an angle of $70.3^{\circ}$ to axis of symmetry, indicating the indenter itself as a whole is conical. In contrast, the real shape of Berkovich indenter is triangular pyramid. Considering the boundary conditions, circumferential displacement in 2D model is constrained and only the displacement in radial direction is permitted. By comparison, constrained circumferential displacement just appears on the symmetry plane and deformation can be expanded in both circumferential and radial direction within matrix in $3 \mathrm{D}$ model. Considering above variations and the fact that 2D model cannot be utilized to discuss the orientation dependent properties due to its rotational symmetry, a 3D simulation seems preferable, even though computational time is considerably higher.

The Berkovich indenter is a triangular-based pyramid having a threefold symmetry. The load is applied along the axis of the indenter; thus the load symmetry is the same as the geometric one. For these considerations, a three-dimensional model is defined only by one-third of the entire system. The 3D model setup is shown in Figure 4. In the simulations, the indenter is modeled as a rigid body. This is justified as the diamond indenter has a modulus of $1141 \mathrm{GPa}$. In this paper, the dimension of material in FEM model is $2 \mathrm{~mm} \times 2 \mathrm{~mm} \times$ $1 \mathrm{~mm}$, which is much larger than maximum indentation displacement. As for the mesh section, size of mesh is generally a compromise between the computational cost and the solution accuracy. Based on various deformation levels, 


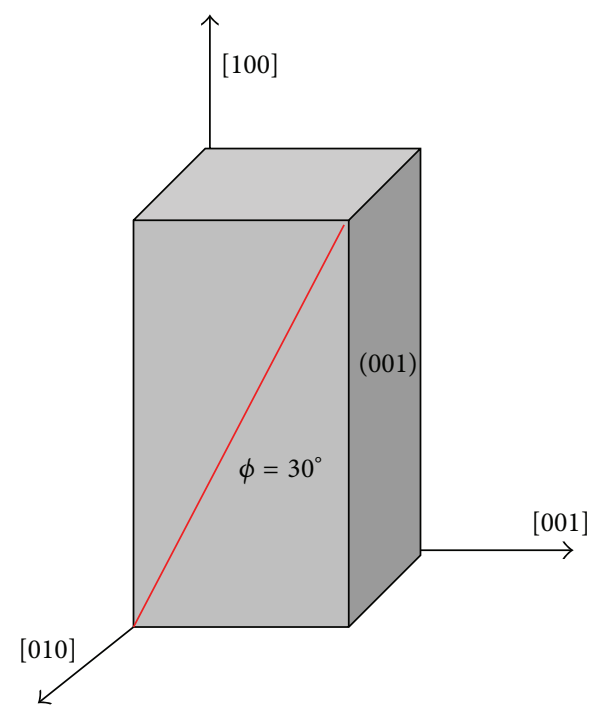

(a)

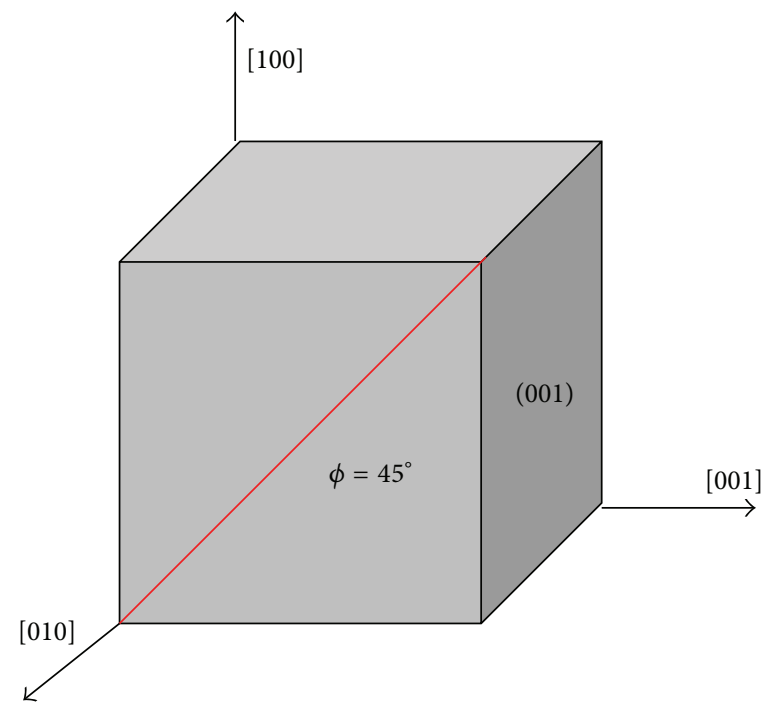

(b)

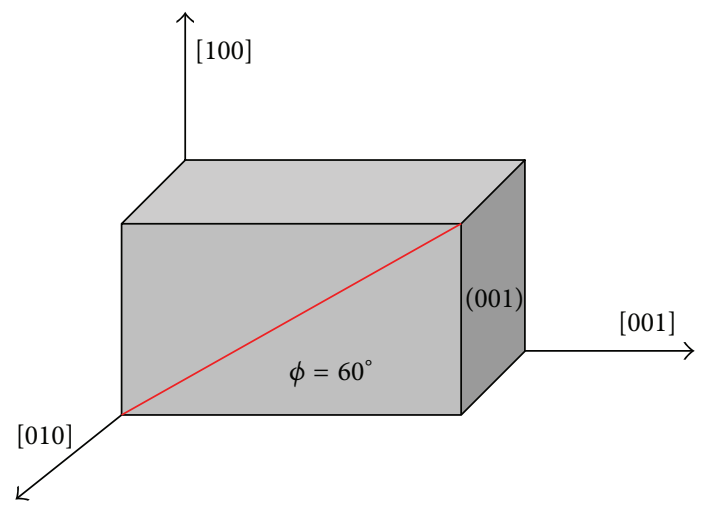

(c)

FIGURE 3: Schematic diagram of specimens with different cutting angles: (a) $30^{\circ}$; (b) $45^{\circ}$; (c) $60^{\circ}$.

TABLE 2: MIT condition.

\begin{tabular}{|c|c|c|c|c|c|c|c|c|c|}
\hline Max load (mN) & 500 & 1000 & 1500 & 2000 & 2500 & 3000 & 3500 & 4000 & 4500 \\
\hline Velocity $(\mathrm{mN} / \mathrm{s})$ & & 17.2842 & & \multicolumn{2}{|c|}{34.5684} & \multicolumn{2}{|c|}{51.8527} & \multicolumn{2}{|c|}{103.7053} \\
\hline
\end{tabular}

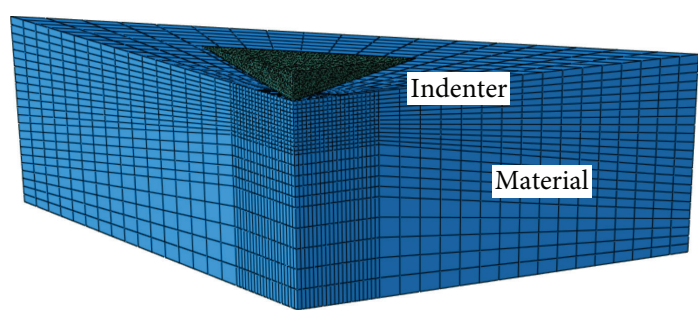

Figure 4: Microindentation model setup.

a finer mesh is used near the indenter tip and a coarser mesh for farther regions. And the element of material is C3D8R, while that of indenter is R3D3. The effect of friction coefficient on the nanoindentation behavior has been investigated by Liu et al. [47], illustrating that the friction does not change the load-displacement relationship. A lower friction contact pair is defined by two contact surfaces with associated nodes between the indenter and the material. In addition, boundary conditions are defined as an element on two symmetry planes parallel to indenter movement direction constrained, only able to expand along radical and axial direction with the help of cylindrical coordinate. But the elements on the bottom of material were defined as having no displacement in any direction.

\section{Experimental Results and Analysis}

4.1. Microhardness and Tensile Strength. The load-displacement curves ( $P$ - $h$ curves) of crystal plane (405) under loading velocity of $17.284 \mathrm{mN} / \mathrm{s}$ are shown in Figure 5. It can be found that curves of various loads show similar shape, which indicates a better repeatability of indentation tests. Different from the nanoindentation test, no "pop-in" size by the abrupt 


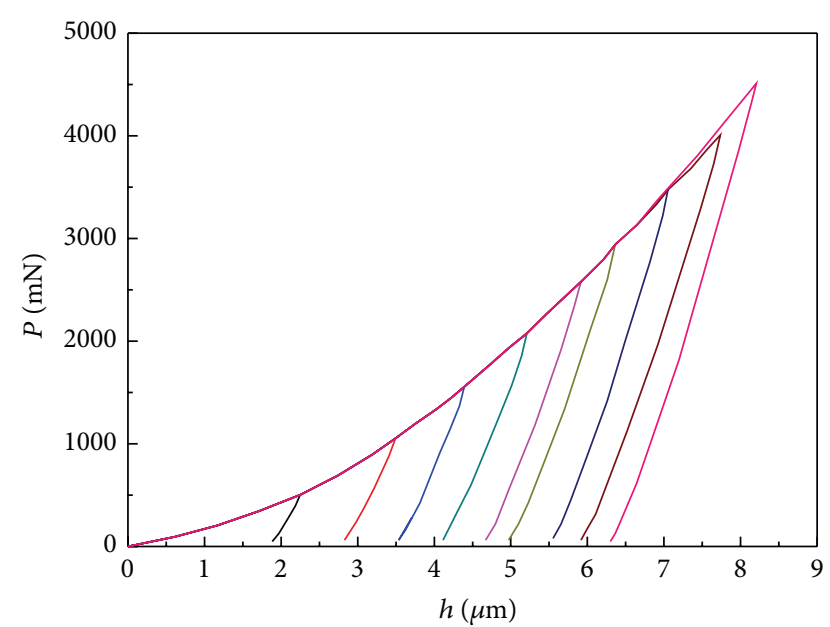

Figure 5: $P$ - $h$ curves of (405) under velocity of $17.284 \mathrm{mN} / \mathrm{s}$.

plastic flow generated by the high density of dislocation nucleation and propagation is observed in microindentation [48]. Based on these curves, micromechanical parameters $(H$, $E, \sigma_{y}, \sigma_{b}$, and $n$ ) can be obtained according to equations mentioned in Section 2.

Based on (24), microhardness of four different crystal planes ((001), (215), (405), and (605)) has been calculated. The results are shown in Figure 6.

It can be seen from Figure 6 that $H$ of each crystal plane under different velocities is almost the same although data of (001) with $51.8527 \mathrm{mN} / \mathrm{s}$ derives from others slightly, which indicates that microindentation loading velocities had little influence on the results of $H$. And the similar phenomenon was founded in Ti-6Al-4V alloy [49]. Therefore, loading velocity of $17.2842 \mathrm{mN} / \mathrm{s}$ was used in the following investigation. $H$ of different crystal planes corresponding to $17.2842 \mathrm{mN} / \mathrm{s}$ was shown in Figure 7.

According to Figure 7, $\mathrm{H}$ of four crystal planes evidently decreases with the increase of maximum load. The phenomenon that indentation depth increases with increase of maximum load confirms the reduction of $H$. In addition, the apparent drop of $H$ occurs when the loads are less than $2000 \mathrm{mN}$. When loads are above $2000 \mathrm{mN}$, their values reduce up to $8 \%$. This phenomenon is attributed to indentation size effects (ISE) caused by geometrically necessary dislocations (GNDs). At the micro/nanoscales, GNDs are large enough and arranged periodically and regularly to cause strong obstacles to slip. GNDs have a strengthening effect on hardness and enhance indurations of material [50]. But values of GNDs have a decreasing tendency with the increase of $h$, which can be demonstrated by the equation of density of GNDs $\left(\rho_{G}\right)$ for a Berkovich indenter:

$$
\rho_{G}=\frac{3 \tan ^{2} \theta}{2 b h}
$$

where $\theta$ is the angle between surface of the indenter and plane of the surface with the value of $19.7^{\circ}$ for Berkovich indenter [27].
Moreover, Nix and Gao proposed a new model of $H$ and $h$, based on Taylor dislocation and geometrically necessary dislocation model $[43,51]$ :

$$
\frac{H}{H_{0}}=\sqrt{1+\frac{h^{*}}{h}},
$$

where $h^{*}$ is a length that characterizes the depth dependence of hardness:

$$
\begin{gathered}
H_{0}=3 \sqrt{3} \alpha \mu b \sqrt{\rho_{S}}, \\
h^{*}=\frac{81}{2} b \alpha^{2} \tan ^{2} \theta\left(\frac{\mu}{H_{0}}\right)^{2},
\end{gathered}
$$

where $\alpha$ is a constant, whose value is $0.3-0.5$.

According to (26) and (27), one can find that when $P$ is low, $h$ is of small value correspondingly. Thus $\rho_{G}$ of region under indenter is considerable and the measured values of $H$ are large. When load is relatively higher, $\rho_{G}$ is in a lower amount and its hardening effect is relatively small on $H$, when $H$ remains almost stable.

As for each crystal plane, $H$ of (001) is close to that of (405), while it is higher than those of (215) and (605). (405) has the largest values of $H$, followed by (001) and (215), which can be explained by dislocation hardening mechanism. It is well known that there are four mechanisms existing in metallic: solid solution hardening, dislocation hardening, boundary hardening, and precipitation hardening. In this paper, single crystal that has no crystal boundary was investigated and the solid solution and precipitation hardening can be ascribed to dislocation movement. Therefore, dislocation hardening is the dominant factor on $H$. In the literature, the density equation of dislocation $(\rho)$ has been proposed:

$$
\rho=\frac{3 \tan ^{2} \theta}{2 b}\left(\frac{1}{h}+\frac{1}{h^{*}}\right) .
$$

The statistically stored dislocations density on four crystal planes can be calculated through (29), as shown in Figure 8. It can be seen that (001) has the largest dislocation density among these crystal planes, and second for (405), the lowest for (215). Compared with $H$ of four crystal planes in Figure 7, it is reasonable that $H$ of (605) and (215) is lower than those of other two planes. Because dislocation density is lower, hardening effect caused by dislocation is weaker. However, with regard to $H$ of (001) and (405), $H$ of (405) is larger than that of (001), although $\rho$ of (001) is higher. This phenomenon can be explained by the following facts. For metallic materials with FCC crystal structure, slip easily takes place on the closepacked $\{111\}$ octahedral planes and in the $\langle 110\rangle$ close-packed directions. Generally, for FCC lattice there are four slip planes and three corresponding slip directions, namely, posing twelve slip systems. But there are eight equivalent $\{111\}\langle 110\rangle$ slip systems on (001) planes, while there is only one equivalent slip system on (405), (605), and (215). Compared with (405), dislocation may extend through different slip systems and hardly pile up due to more slip systems on (001). Therefore, $H$ of (001) is a little lower than that of (405). 


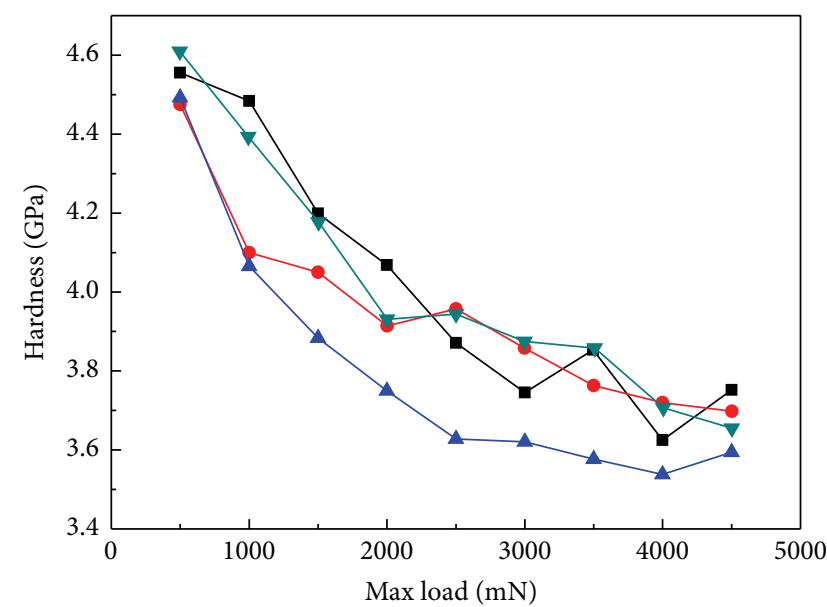

(a)

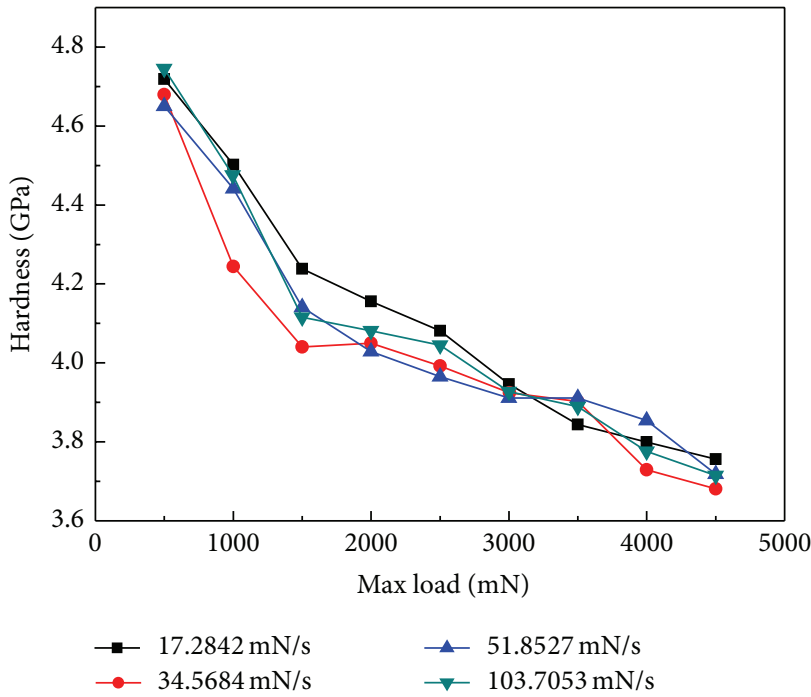

(c)

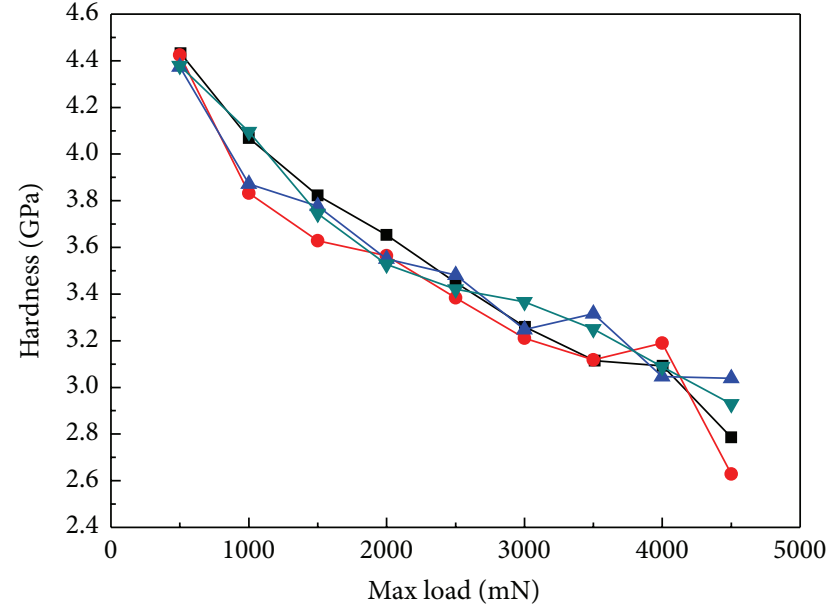

(b)

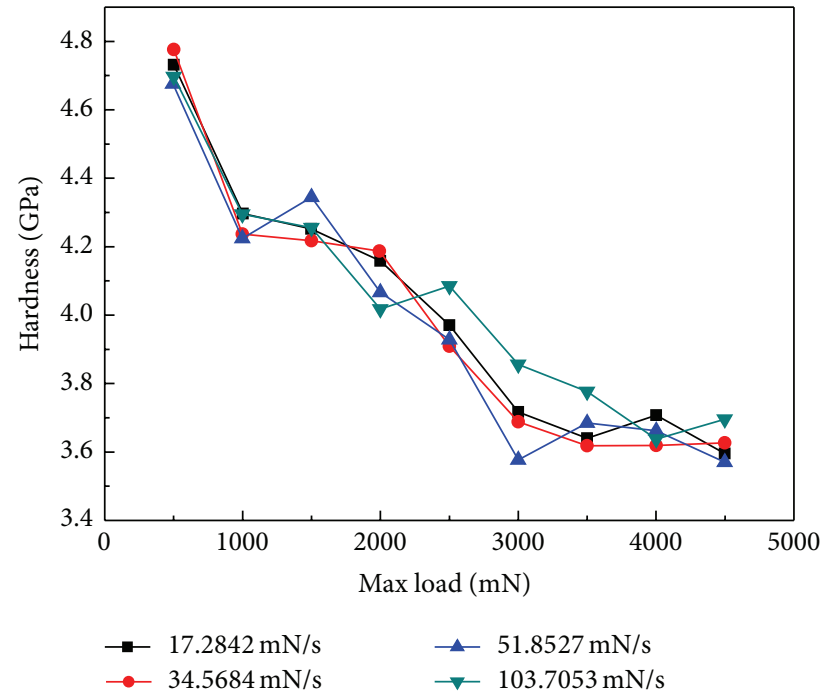

(d)

Figure 6: Microhardness $H$ of different crystal planes under different velocities: (a) (001); (b) (215); (c) (405); (d) (605).

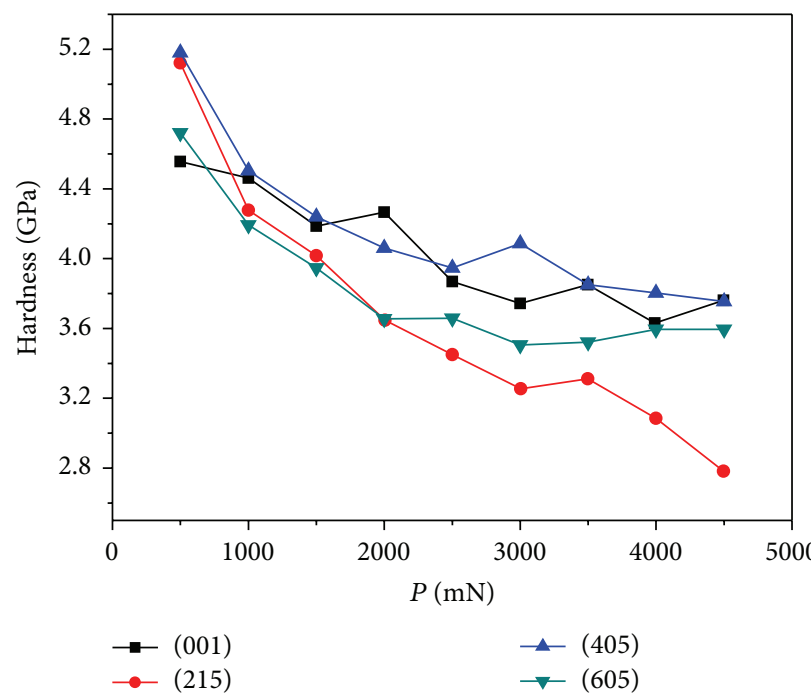

Figure 7: $H$ of different crystal planes under $17.2842 \mathrm{mN} / \mathrm{s}$. 


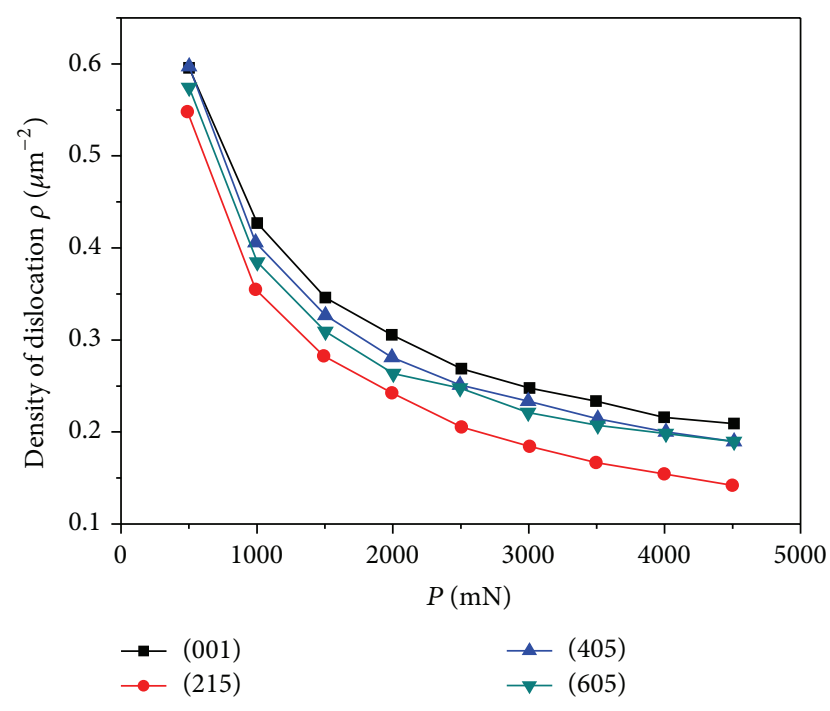

FIGURE 8: Density of dislocation density $\rho$ of four crystal planes.

4.2. Young's Modulus E. Of the various unique mechanical properties of materials, Young's modulus, which is a measure of elasticity, has attracted particular attention. Figure 9 shows Young's modulus of four different crystal planes ((001), (215), (405), and (605)) calculated according to (6).

It can be seen from Figure 9 that the calculated $E$ of each crystal plane under different velocities has similar values, illustrating that microindentation loading speeds had little influence on the results of $E$. And the similar phenomenon was also found in Ti-6Al-4V alloy [49]. Therefore, loading speed with value of $17.2842 \mathrm{mN} / \mathrm{s}$ was used for the following investigation.

Figure 10 gives the values of $E$ from different crystal planes under the loading speed of $17.2842 \mathrm{mN} / \mathrm{s}$. As shown in Figure 10, it can be concluded that $E$ decreases with the increase of $h$ on the whole.

Compared with $H$ of the same planes, $E$ also decreases rapidly with loads below $2000 \mathrm{mN}$. And its values remain almost the same when subjected to the higher loads. The induced damage is responsible for this phenomenon. The reduction of Young's modulus is typically regarded as a characterization of damage evolution and accumulation. When dislocations accumulate or pile up in a certain region, it is easy for stress to concentrate and eventually surpass its threshold. Thus, damage can be easily generated and extended under indentation load, resulting in elastic properties weakening and $E$ decreasing. In addition, when loads are below $2000 \mathrm{mN}$, each of $E$ curves falls quickly due to the high values of $\rho$ (Figure 8 ) and the corresponding rapid damage accumulation. However, when the loads are around $4000 \mathrm{mN}$, fluctuation of $\rho$ is steady and has no obvious effect on variation of $E$.

For each crystal plane, $E$ of (001) is larger than others and (215) has the lowest value. Crystalline structure and theory of metallic plasticity contribute qualitatively to the explanation of diverse $E$ from different crystal plane. For example, for cubic system, the expression for the interplanar spacing $(d)$ is as follows:

$$
\frac{1}{d^{2}}=\frac{j^{2}+k^{2}+l^{2}}{a^{2}},
$$

where $a$ is $0.358 \mathrm{~nm}$ for DD99.

According to (30), the interplanar spacing of (001), (215), (405), and (605) is $0.358 \mathrm{~nm}, 0.0703 \mathrm{~nm}, 0.06 \mathrm{~nm}$, and $0.0493 \mathrm{~nm}$, respectively. The greater the interplanar spacing is, the larger the density of atoms on this crystal plane is. The greater interplanar spacing is significantly efficient in driving the movement of atoms on the crystal plane, which poses a larger E. However, this explanation does not work for (405) in comparison with that of (215); this phenomenon needs further research.

According to theory of metallic plasticity, the crystal $E$ can be also obtained through stiffness coefficient and crystal indices [52]. For cubic system, $E$ can be calculated as the following equation:

$$
\begin{gathered}
\frac{1}{E}=S_{11}-2 S_{A} \frac{(j k)^{2}+(j l)^{2}+(k l)^{2}}{\left(j^{2}+k^{2}+l^{2}\right)}, \\
S_{A}=S_{11}-S_{12}-\frac{S_{44}}{2} .
\end{gathered}
$$

For the same material, $E$ with different crystal orientation and planes mainly depends on

$$
\frac{\left[(j k)^{2}+(j l)^{2}+(k l)^{2}\right]}{\left(j^{2}+k^{2}+l^{2}\right)^{2}} .
$$

For crystal nickel-based DD99, value of $S_{A}$ is negative. According to (32), the value of (001) is 0, which is the smallest one among four crystal planes, while (605) is having the largest data of 0.24187 . So (001) has the largest $E$, but $E$ of (605) is relatively lower.

4.3. Elastic-Plastic Constitutive Model. According to equations in Section 2.1, the values of $\sigma_{y}$ and $n$ of (405) under different loads are shown in Figure 11. It is evident that they remain constant regardless of the different loads.

As shown in Figure 12, values of $\sigma_{y}$ and $n$ are shown in bar graph. It can be found that $\sigma_{y}$ of (215) is the largest, followed successively by (605) and (001). However, the values of $n$ show the opposite tendency. That is, $n$ of (215) is the lowest, followed by (605), and that of (001) is the largest.

It is well known that $\sigma_{y}$ is the strength assessing the ability to resist the plastic deformation. And for materials with power hardening law, $n$ is used as a parameter evaluating a kind of ability that maintains homogeneous deformation. The higher $n$ of certain material, the better compatibility of deformation of material. The differences of $\sigma_{y}$ on four crystal planes can be explained by Schmid's law.

In Figure 13, a typical uniaxial tensile stress $\sigma$ exerted on a metal cylinder is shown. $A_{0}$ is the area normal to the axial force $F$ and $A_{1}$ is the area of the slip plane on which the resolved shear force $F_{r}$ is acting. $\phi$ is the angle 


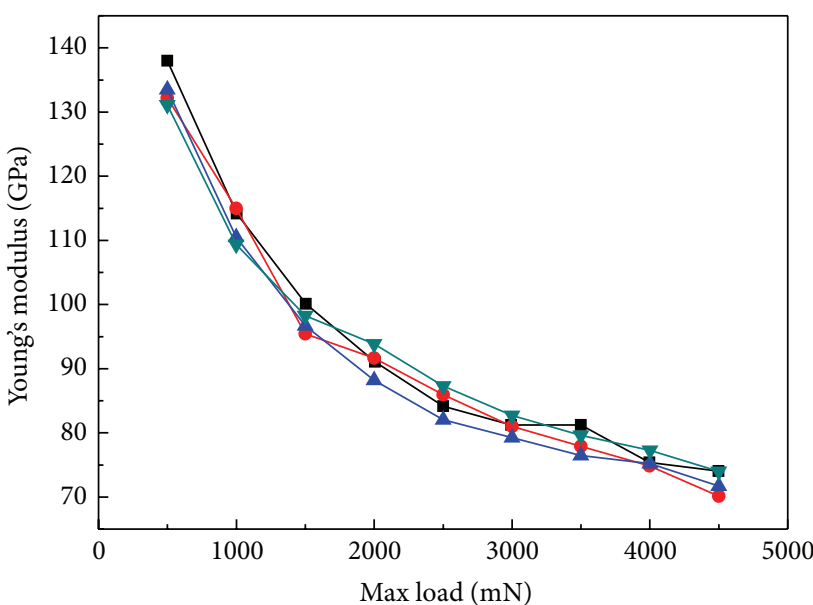

(a)

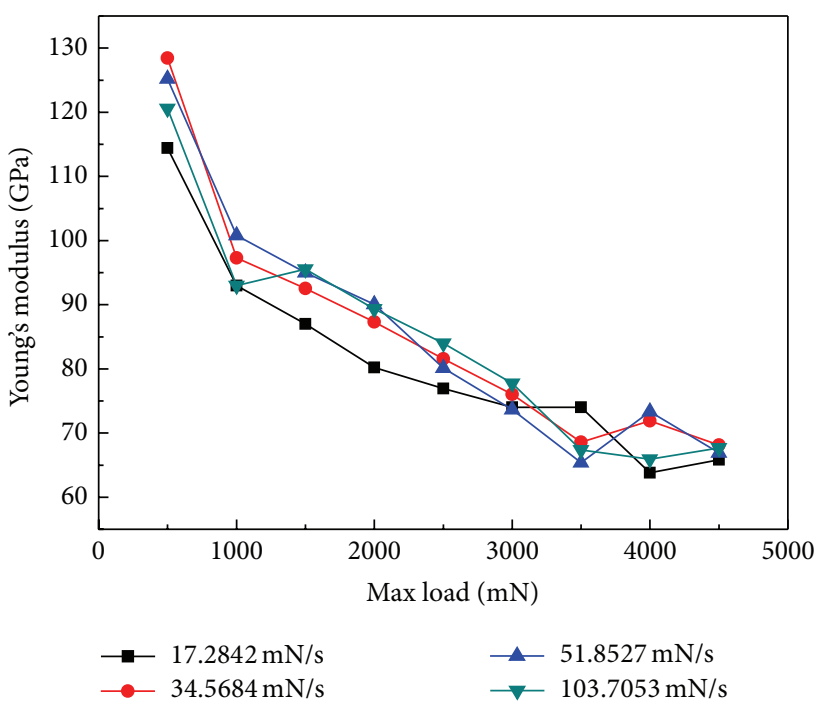

(c)

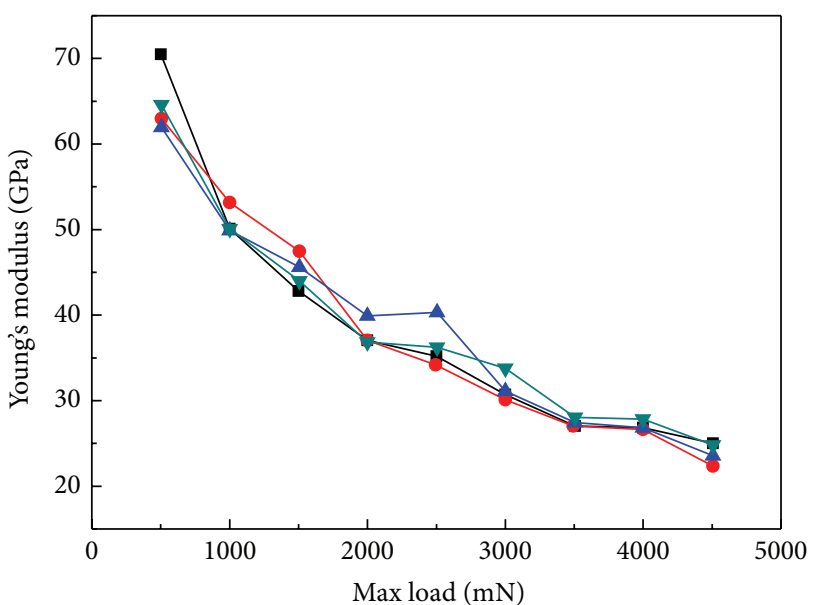

(b)

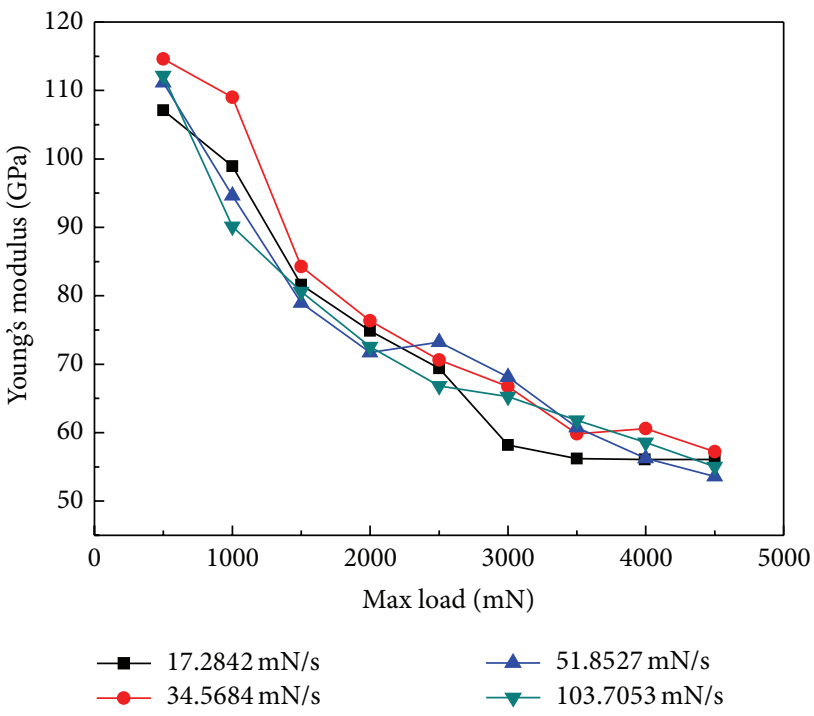

(d)

Figure 9: Young's modulus $E$ of different crystal planes under different speeds: (a) (001); (b) (215); (c) (405); (d) (605).

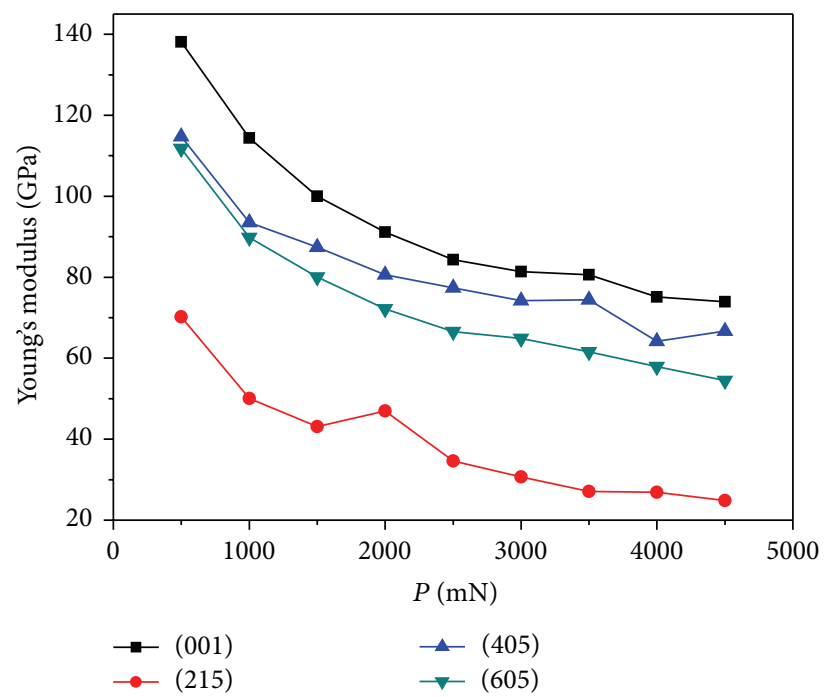

FIGURE 10: $E$ of different crystal planes under $17.2842 \mathrm{mN} / \mathrm{s}$. 


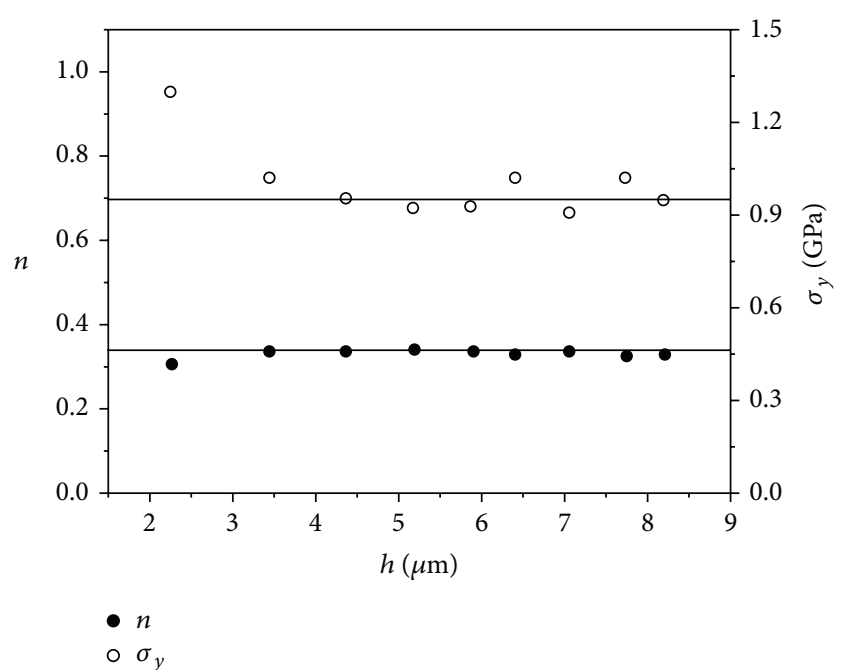

FIGURE 11: Values of $\sigma_{y}$ and $n$ at different indentation depths $h$ of (405).

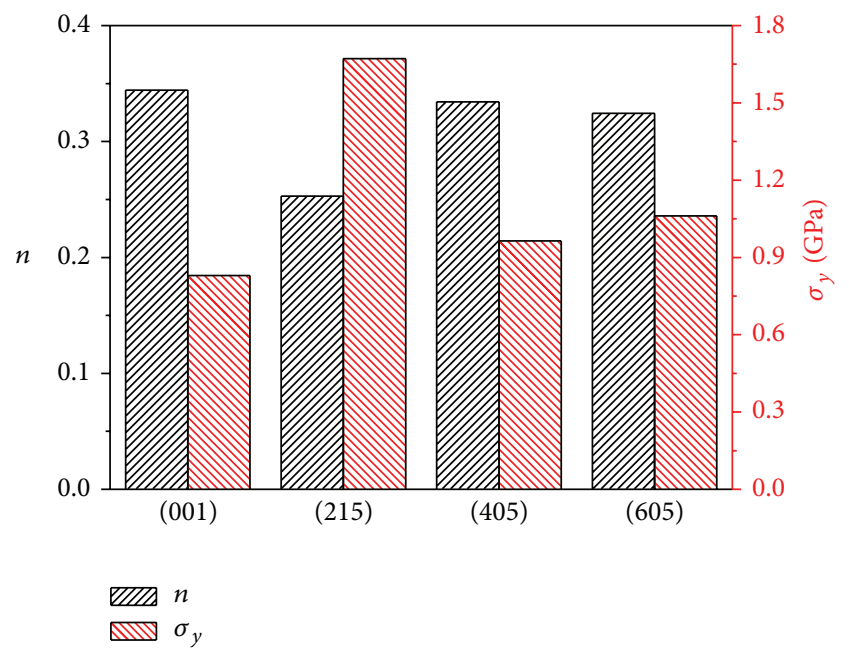

FIGURE 12: $\sigma_{y}$ and $n$ of four different crystal planes.

between $F$ and the normal to the slip plane area $A_{1}$, and $\lambda$ is the angle between $F$ and the slip direction. For activating dislocations to move in the slip system, a sufficient resolved shear stress $\left(\tau_{r}\right)$ in the slip direction must be produced, and $\tau_{r}$ is computed as

$$
\tau_{r}=\frac{F_{r}}{A_{1}}=\frac{F \cos \lambda}{A_{0} / \cos \phi}=\frac{F}{A_{0}} \cos \lambda \cos \phi=\sigma \cos \lambda \cos \phi .
$$

This is called Schmid's law. $m$ is called Schmid factor and defined as follows:

$$
m=\cos \lambda \cos \phi
$$

$m, \sigma_{y}$, and $n$ are shown in Table 3 .

$\tau_{r}$ is a constant for a previous known lattice, and independent of the orientation of $F$, it can be inferred that $\sigma$ is larger,

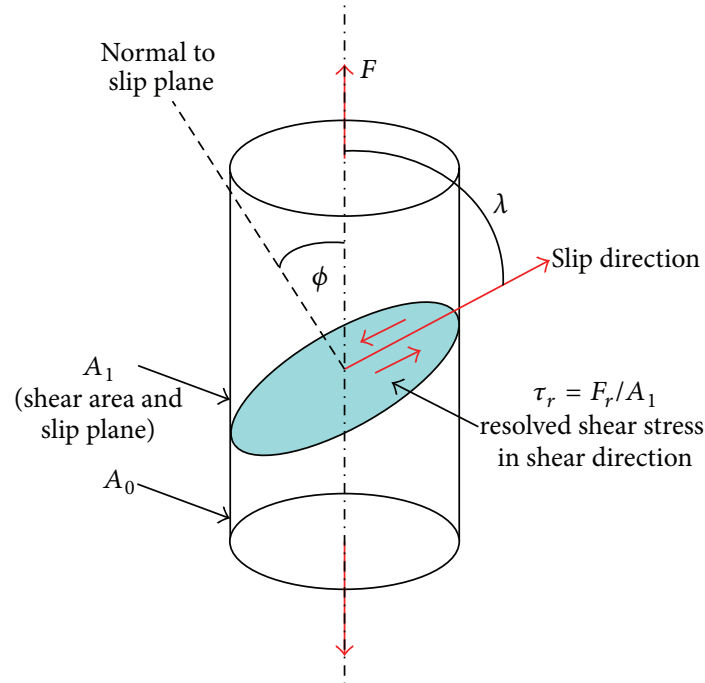

FIGURE 13: Schematic diagram of uniaxial tension model.

TABLE 3: $m, \sigma_{y}$, and $n$ of different crystal planes.

\begin{tabular}{lccc}
\hline Crystal indices & $n$ & $\sigma_{y}(\mathrm{GPa})$ & $m$ \\
\hline$(001)$ & 0.3449 & 0.8248 & 0.408 \\
$(215)$ & 0.2529 & 1.6701 & 0.435 \\
$(405)$ & 0.3338 & 0.9667 & 0.448 \\
$(605)$ & 0.3242 & 1.0585 & 0.442 \\
\hline
\end{tabular}

if $m$ is smaller according to (33) and (34). Therefore, the fact that $\sigma$ of (215) is larger than that of (605), which is followed by (405), can be understandable, because $m$ of (215), (605), and (405) increases sequentially. With particular emphasis on $m$ of (001) which is the lowest, it has eight equivalent $\{111\}\langle 110\rangle$ slip systems, while there is only one equivalent slip system on (405), (605), and (215). For FCC singlecrystal structure, Schmid's law is no longer valid, regardless of potential slip systems. When value and orientation of $F$ are appropriate, $\tau_{r}$ of two or more slip systems can be achieved, which makes the situation complicated, and Schmid law does not work anymore.

For (001) crystal having eight equivalent $\{111\}\langle 110\rangle$ slip systems and a relatively lower $\sigma_{y}$, the dislocations can extend easily and the deformation resistance is low, resulting in better compatibility of uniform deformation. So, it has the largest $n$. With regard to (215), (605) and (405) who yield only one equivalent slip system, the yield strength decrease in order, namely, compatibility of deformation of (405) is the best, followed by (605). And that of (215) is the worst of all. Therefore, $n$ of (405) is larger than that of (605).

Based on (2) and (23), $R$ and $\sigma_{b}$ along with other parameters representing elastic-plastic properties can be obtained in Table 4.

Mechanical property parameters, $E, R, n$, and $\sigma_{y}$, were obtained from microindentation experimental data; thus the 
TABLE 4: Elastic-plastic properties parameters.

\begin{tabular}{lcccc}
\hline Crystal indices & $R$ & $n$ & $\sigma_{y}(\mathrm{GPa})$ & $\sigma_{b}(\mathrm{GPa})$ \\
\hline$(001)$ & 3.8941 & 0.3449 & 0.8248 & 1.9110 \\
$(215)$ & 3.3090 & 0.2529 & 1.6701 & 1.8150 \\
$(405)$ & 3.9661 & 0.3338 & 0.9667 & 1.9694 \\
$(605)$ & 3.8123 & 0.3242 & 1.0585 & 1.9133 \\
\hline
\end{tabular}

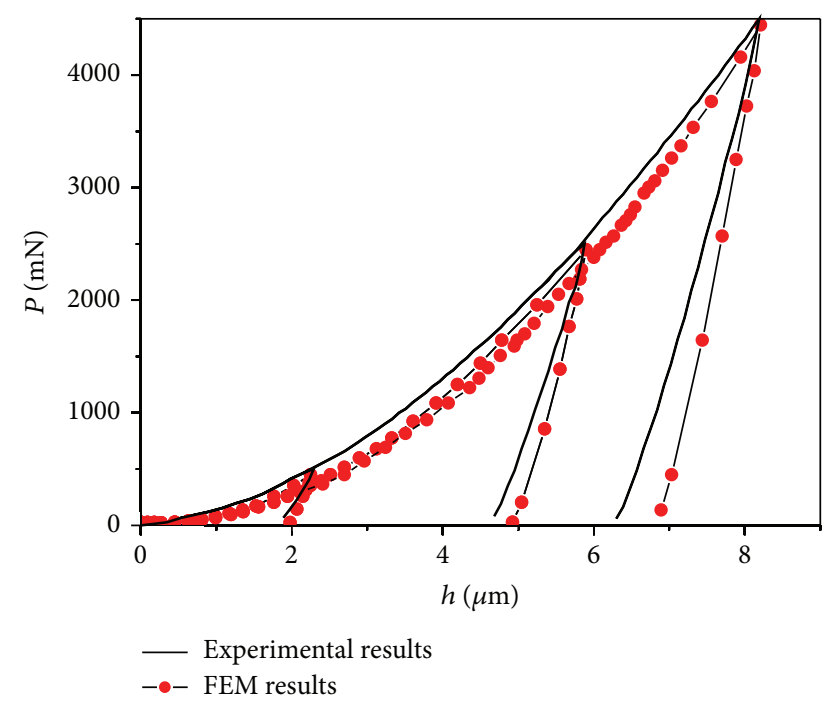

FIgURE 14: Experimental versus computed $P-h$ curves of $500 \mathrm{mN}$, $2500 \mathrm{mN}$, and $4500 \mathrm{mN}$ on (405).

elastic-plastic equations of DD99 on different crystal planes can be obtained as

$$
\begin{aligned}
& \text { Crystal plane (001) } \quad \sigma= \begin{cases}137.9 \varepsilon, & \\
3.8941 \varepsilon^{0.3449}, & \sigma \geq 824.8,\end{cases} \\
& \text { Crystal plane (215) } \quad \sigma= \begin{cases}70.332 \varepsilon, & \sigma \leq 1670.1 \\
3.309 \varepsilon^{0.2529}, & \sigma \geq 1670.1,\end{cases} \\
& \text { Crystal plane (405) } \quad \sigma= \begin{cases}114.3465 \varepsilon, & \sigma \leq 966.7 \\
3.9661 \varepsilon^{0.3338}, & \sigma \geq 966.7,\end{cases} \\
& \text { Crystal plane (605) } \quad \sigma= \begin{cases}112.414 \varepsilon, & \sigma \leq 1058.5 \\
3.8123 \varepsilon^{0.3242}, & \sigma \geq 1058.5 .\end{cases}
\end{aligned}
$$

\section{Verification of Elastic-Plastic Model}

Simulation calculations have been performed by using the commercial finite element software ABAQUS. The experimental and FEM results of $500 \mathrm{mN}, 2500 \mathrm{mN}$, and $4500 \mathrm{mN}$ on crystal plane (405) were shown in Figure 14. The experimental curves agreed well with computed $P-h$ curves, which indicates that above elastic-plastic equations of DD99 obtained by MIT are valid and 3D FEM model of indentation can fully describe and simulate microindentation process.

Although FEM results deviate from experimental results slightly, it is of great importance to focus on their difference.
In order to illustrate cause of deviation to achieve better simulations in the future, experimental and FEM results of $2500 \mathrm{mN}$ on different crystal planes were shown in Figure 15.

As shown in Figure 15, it can be concluded that FEM results seem like experimental data moving right. To be more specific, FEM results have various degrees of deviation from experimental results during the loading process, especially in the middle process of the loading. This phenomenon can be explained by Kick's law (Equation (4)) and decrease of $E$ along with increase of $h$.

There is a relationship between $H$ and $\sigma_{y}$ originally suggested by Tabor [53]:

$$
H=C_{\theta} \sigma_{y} .
$$

According to (9) and (24), $P_{m}$ can be expressed as follows:

$$
P_{m}=\omega \sigma_{y} h_{m}^{2}
$$

where $\omega$ is a constant.

Therefore, Kick's law seems to be reasonable. However, microindentation test is not an ideal plastic deformation process. ISE exists in the process of microindentation as discussed above, resulting in decrease of $H$. As $H$ is the function of $h$ shown in (26), $\sigma_{y}$ is also a function of $h$ according to (37). And the relationship between $P_{m}$ and $h$ is no longer quadratic function. When the load is low, ISE is obvious [54] and error of results from Kick's law is larger compared with those under high load. In order to prove it, the experimental and FEM results of (405) under $500 \mathrm{mN}$ and $2500 \mathrm{mN}$ were utilized, as shown in Figure 16. Besides, the lower load yields a poor accuracy between simulated and experimental results in comparison with the higher load, which may be due to the transition of contact modes from purely elastic under lower loads to elastic/plastic under higher loads. Jian et al. [22, 55, 56] have maintained that the behaviors during indentation can be roughly divided into two stages by the variation of microhardness. Namely, the hardness initially increases with the penetration depth due to the transition between purely elastic and elastic/plastic contact.

Also the decrease of $E$ along with increase of $h$ may also be blamed for the difference between experimental and FEM results. In FEM model, the selection of $E$ is a complicated question. As shown in Figure 10, $E$ of four crystal planes decreases with the increase of $h$ due to damage, $E$ actually changes a little with high load, and the value of $E$ with high load is used in FEM model. In the preliminary stage of indentation, $E$ of materials is higher than that used in FEM model. According to stress-strain relationship in the elastic stage, the higher $\varepsilon$ is corresponding to the smaller $E$. So $h$ of FEM is larger than that of experimental data.

With regard to unloading process, the slope of unloading curve is related with $E$ according to (13). And it can be found that all the unloading curves of FEM results are parallel to that of experimental data (Figure 15), indicating that the difference of unloading process is attributed to the error of $h$ in loading process and the selection of $E$ in FEM model is reasonable.

In order to interpret the matching degree of $P$ - $h$ curves in FEM results and experimental data quantitatively, the predictability of the applied load is further quantified employing 


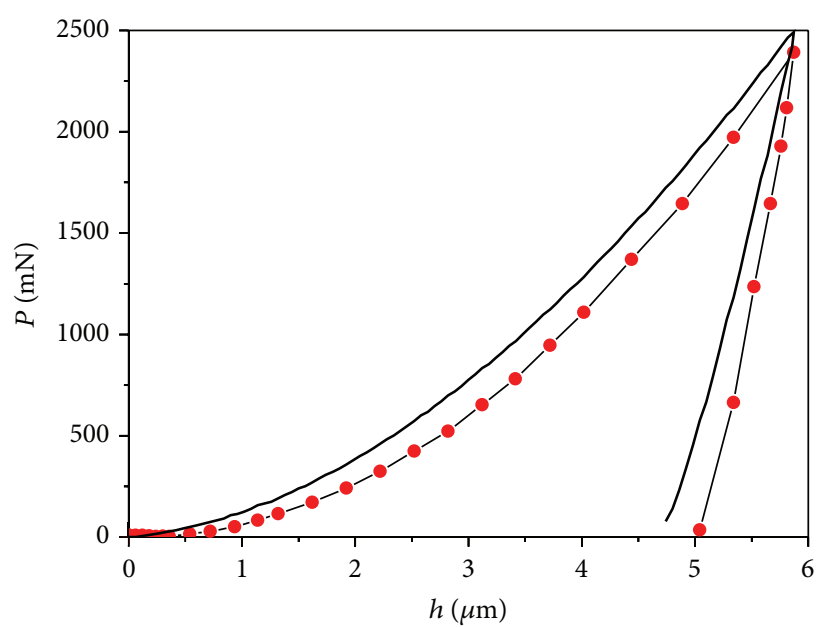

(a)

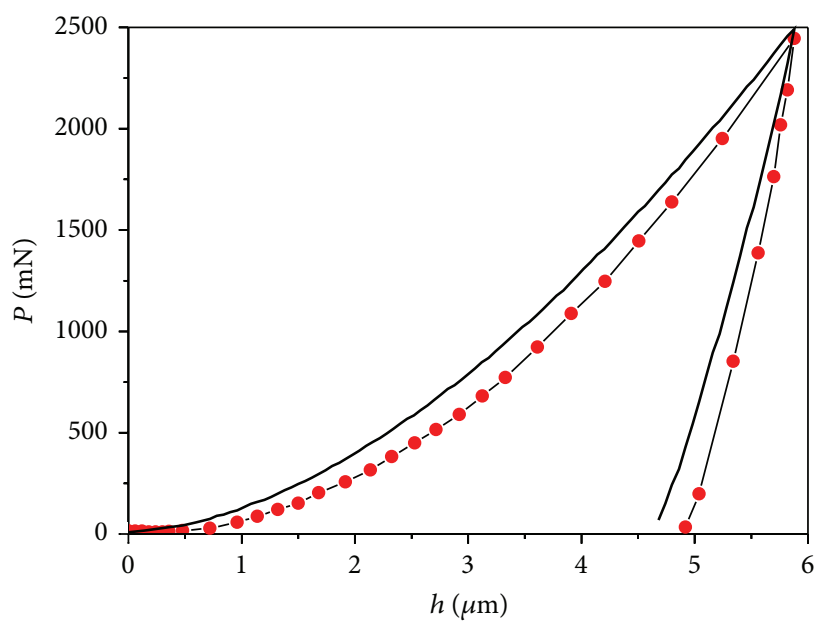

- Experimental results

- - FEM results

(c)

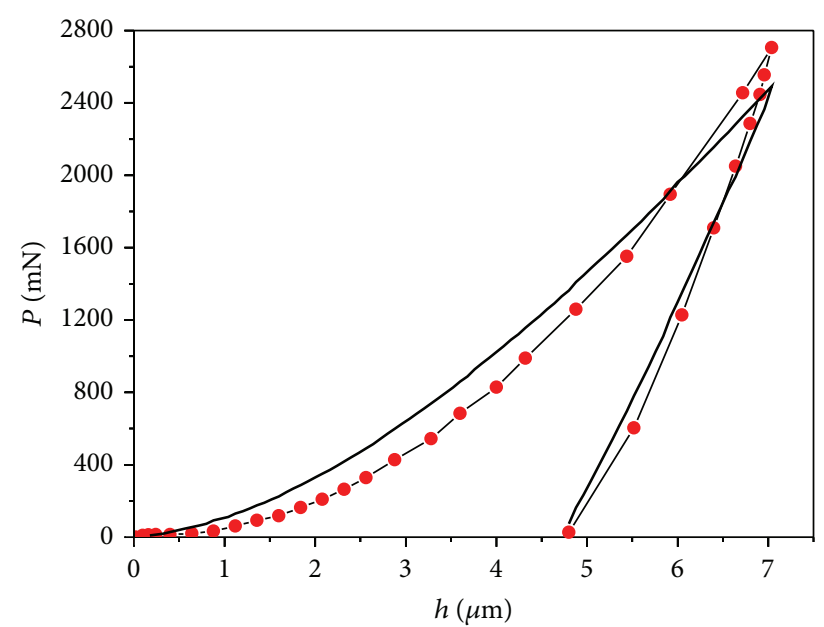

(b)

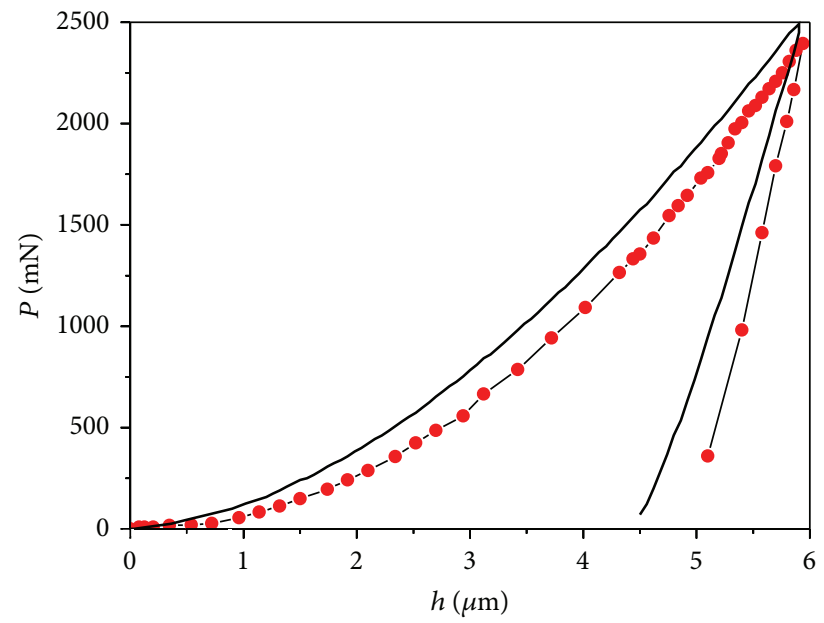

Experimental results

- - FEM results

FIGURE 15: Experimental and FEM results of $2500 \mathrm{mN}$ on different crystal planes: (a) (001); (b) (215); (c) (405); (d) (605).

standard statistical parameters correlation coefficient $(U) . U$ was a commonly used statistic and provides information on the dispersion between the experimental and the computed values. It was expressed as $[57,58]$

$$
U=\frac{\sum_{i=1}^{N}\left(P_{\exp }^{i}-\bar{P}_{\exp }\right)\left(P_{p}^{i}-\bar{P}_{p}\right)}{\sqrt{\sum_{i=1}^{N}\left(P_{\exp }^{i}-\bar{P}_{\exp }\right)^{2} \sum_{i=1}^{N}\left(P_{p}^{i}-\bar{P}_{p}\right)^{2}}}
$$

where $P_{\exp }$ is the experimental indenter load, $P_{p}$ is the predicted indenter load, and $\bar{P}_{\exp }$ and $\bar{P}_{p}$ are the mean values of $P_{\exp }$ and $P_{p}$, respectively.

According to literature [59], the predictability of the matching degree of $P$ - $h$ curves can also be quantified by the average absolute relative error (AARE) and the results of $U$ and AARE are as shown in Table 5:

$$
\operatorname{AARE}(\%)=100 \times \frac{1}{N} \sum_{i=1}^{N}\left|\frac{P_{\exp }^{i}-P_{p}^{i}}{P_{\exp }^{i}}\right| .
$$

\section{Conclusions}

Microindentation measurements using a sharp Berkovich indenter on single-crystal nickel-based superalloy DD99 of four crystallographic orientations, that is, (001), (215), (405), and (605), were made to determine the load-displacement relations. Some material parameters reflecting the micromechanical behavior of DD99, such as microhardness $H$, Young's modulus $E$, yield stress $\sigma_{y}$, strain hardening component $n$, and tensile strength $\sigma_{b}$, can be obtained from loaddisplacement relations. Subsequently, the process of MIT is simulated using 3D FEM based on the above parameters. 


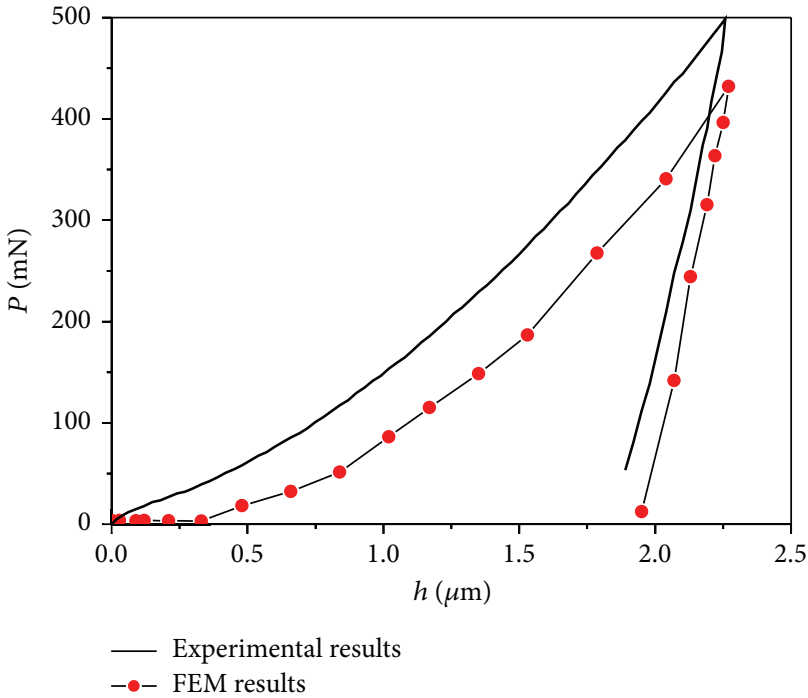

(a)

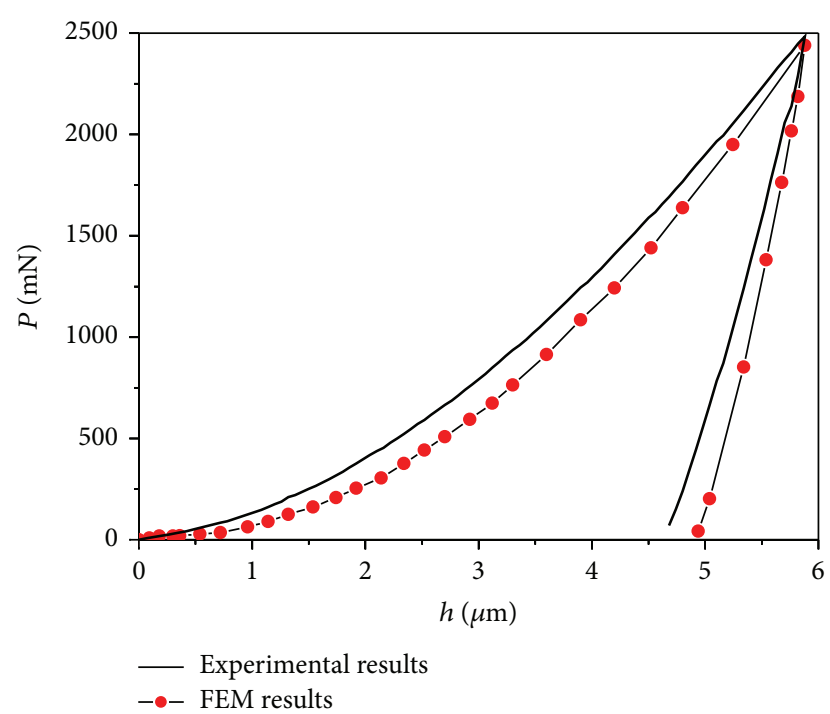

(b)

Figure 16: Experimental and FEM results of (405) with different loads: (a) $500 \mathrm{mN}$; (b) $2500 \mathrm{mN}$.

TABLE 5: Error analysis of four different crystal planes.

\begin{tabular}{lcc}
\hline Crystal indices & $\begin{array}{c}\text { Correlation } \\
\text { coefficient } U\end{array}$ & $\begin{array}{c}\text { Average absolute } \\
\text { relative error (AARE } \\
\%)\end{array}$ \\
\hline$(001)$ & 0.9884 & $15 \%$ \\
$(215)$ & 0.9914 & $14 \%$ \\
$(405)$ & 0.99024 & $14.3 \%$ \\
$(605)$ & 0.992515 & $12.8 \%$ \\
\hline
\end{tabular}

Eventually, the influence of crystal orientations on micromechanical properties can be concluded as follows.

(1) $H$ of four different crystal planes evidently decreases with the increase of $h$. The crystal plane (405) has the largest micro-hardness values, followed by (001). $H$ of (215) is the lowest. This phenomenon is related to dislocation hardening.

(2) $E$ of these planes decreases with the increase of $h$. (001) has the largest $E$, followed by (405). And $E$ of (215) is the lowest, which is attributed to the fact that (001) has the largest interplanar spacing and smallest crystal variable.

(3) $n$ is inversely correlated with $\sigma_{y}$ on all these planes. $\sigma_{y}$ of (215) is the largest among four crystal planes, followed by (605), and (001) has the lowest value. However, $n$ of (215) is the lowest, followed by (605), and that of (001) is the largest. It can be explained by Schmid's factor $(m)$ and the larger $m$ crystal plane has and the lower $\sigma_{y}$ it possesses. In addition, $\sigma_{b}$ on four planes was calculated and it is similar except for (215).

Although FEM results deviate slightly from experimental results, they can be used as sufficient evidences indicating the accuracy of 3D FEM model and material elastic-plastic model founded from MIT.

\section{Nomenclature}

$\begin{array}{ll}A: & \text { Cross-sectional area, } \mathrm{mm}^{2} \\ A_{b}: & \text { Cross-sectional area corresponding to } \\ a: & \sigma_{b}, \mathrm{~mm}^{2} \\ B \text { and } t: & \text { Lattice constant } \\ b: & \text { Fitting coefficients } \\ C: & \text { Burgers vector } \\ & \text { A variable related to material properties } \\ C_{\theta}: & \text { as well as indenter geometry } \\ E: & \text { Constraint factor } \\ E^{*}: & \text { Elastic modulus, MPa } \\ & \text { Effective elastic modulus of damaged } \\ H: & \text { material, MPa } \\ H_{0}: & \text { Microhardness, kg.mm } \\ & \text { microhardness regardless of strain } \\ h: & \text { gradient plasticity, kg.mm } \\ h_{f}: & \text { Indenter displacement, } \mu \mathrm{m} \\ h, k, \text { and } l: & \text { Residual depth after unloading, } \mu \mathrm{m} \\ m: & \text { Miller indices } \\ n: & \text { Schmid factor } \\ P: & \text { Strain hardening exponent } \\ R: & \text { Indenter load, mN } \\ S_{11}, S_{12}, \text { and } S_{44}: & \text { Independent elastic compliance } \\ & \text { constant. }\end{array}$

\section{Greek Letters}

$\varepsilon:$ True strain

$\varepsilon_{y}$ : Corresponding strain to initial yield stress

$\varepsilon_{b}$ : Strain corresponding to $\sigma_{b}$ 
$\sigma_{y}:$ Initial yield stress, $\mathrm{MPa}$

$\sigma_{c}:$ Representative stress, $\mathrm{MPa}$

$\sigma_{b}$ : Ultimate tensile strength, MPa

$\bar{\sigma}$ : Flow stress, $\mathrm{MPa}$

$v$ : Poisson's ratio

$\mu$ : Shear modulus, $\mathrm{MPa}$

$\rho_{S}$ : Density of statistically stored dislocations.

\section{Conflict of Interests}

The authors declare that there is no conflict of interests regarding the publication of this paper.

\section{Acknowledgments}

The authors would like to express their sincere thanks for the research grants supported by the National Natural Science Foundation of China (Grant no. 51275414), the Aeronautical Science Foundation of China (Grant no. 2011ZE53059), and the Graduate Starting Seed Fund of Northwestern Polytechnic University (Grant no. Z2014007).

\section{References}

[1] G. L. Erickson, "Single crystal nickel-based superalloy," Google Patents, 1994.

[2] A. Sato, Y.-L. Chiu, and R. C. Reed, "Oxidation of nickel-based single-crystal superalloys for industrial gas turbine applications," Acta Materialia, vol. 59, no. 1, pp. 225-240, 2011.

[3] C. Lane, "Introduction," in The Development of a 2D Ultrasonic Array Inspection for Single Crystal Turbine Blades, Springer Theses, pp. 1-12, Springer, 2014.

[4] J.-J. Yu, X.-F. Sun, N.-R. Zhao, T. Jin, H.-R. Guan, and Z.-Q. Hu, "Effect of carbon on microstructure and mechanical properties of DD99 single crystal superalloy," Transactions of Nonferrous Metals Society of China, vol. 16, pp. 1973-1977, 2006.

[5] Z.-H. Yu, L. Liu, X.-B. Zhao, W.-G. Zhang, J. Zhang, and H.-Z. $\mathrm{Fu}$, "Advance in research of carbon effect on single crystal Nibase superalloy," Foundry, vol. 58, no. 9, p. 10, 2009.

[6] T.-B. Wu, X.-F. Yu, Y.-L. Man et al., "Burning loss of carbon and influence factors of oxygen content during vacuum induction melting," Foundry, vol. 62, no. 1, pp. 1-3, 2013.

[7] J. S. Wan and Z. F. Yue, "A low-cycle fatigue life model of nickelbased single crystal superalloys under multiaxial stress state," Materials Science and Engineering A, vol. 392, no. 1-2, pp. 145149, 2005.

[8] H. U. Hong, J. G. Yoon, B. G. Choi, I. S. Kim, and C. Y. Jo, "On the mechanism of secondary reaction zone formation in a coated nickel-based single-crystal superalloy containing ruthenium," Scripta Materialia, vol. 69, no. 1, pp. 33-36, 2013.

[9] D. Shi, C. Dong, and X. Yang, "Constitutive modeling and failure mechanisms of anisotropic tensile and creep behaviors of nickel-base directionally solidified superalloy," Materials \& Design, vol. 45, pp. 663-673, 2013.

[10] P. Caron, T. Khan, Y. Ohta, and Y. Nakagawa, "Creep deformation anisotropy in single crystal superalloys," in Superalloys 1988, pp. 215-224, TMS, Warrendale, Pa, USA, 1988.

[11] M. He, H. Li, and J. Nie, "An investigation on creep/fatigue damage characteristics of single-crystal DD6 at high temperature," Gas Turbine Experiment and Research, vol. 15, no. 2, pp. 24-27, 2002.
[12] J. Z. Yi, C. J. Torbet, Q. Feng, T. M. Pollock, and J. W. Jones, "Ultrasonic fatigue of a single crystal Ni-base superalloy at 1000 'C," Materials Science and Engineering A, vol. 443, no. 1-2, pp. 142-149, 2007.

[13] X. Wu, J. H. Zhang, J. L. Liu, T. Jin, Y. B. Xu, and Z. Q. Hu, "Plastic deformation inhomogeneity in a single crystal nickelbase superalloy," Materials Science and Engineering A, vol. 325, no. 1-2, pp. 478-483, 2002.

[14] S. L. Semiatin and T. R. Bieler, "The effect of alpha platelet thickness on plastic flow during hot working of Ti-6Al-4V with a transformed microstructure," Acta Materialia, vol. 49, no. 17, pp. 3565-3573, 2001.

[15] M. Jamal and M. Morgan, "Determination of the mechanical properties of thermally treated recycled glass based on nanoindentation measurement and FEM supported simulation," Key Engineering Materials, vol. 581, pp. 472-477, 2014.

[16] W. B. Lee and Y. P. Chen, "Simulation of micro-indentation hardness of FCC single crystals by mechanism-based strain gradient crystal plasticity,' International Journal of Plasticity, vol. 26, no. 10, pp. 1527-1540, 2010.

[17] L. Wang, X. H. Zhong, J. S. Yang et al., "Finite element simulation of surface micro-indentation behavior of yttria stabilized zirconia thermal barrier coatings with microstructural characteristic of columnar grains and sub-grains based on a nonlinear contact model," Computational Materials Science, vol. 82, pp. 244-256, 2014.

[18] W. Z. Yao, C. E. Krill III, B. Albinski, H.-C. Schneider, and J. H. You, "Plastic material parameters and plastic anisotropy of tungsten single crystal: a spherical micro-indentation study," Journal of Materials Science, vol. 49, no. 10, pp. 3705-3715, 2014.

[19] Y. Y. Lim and M. Munawar Chaudhri, "The influence of grain size on the indentation hardness of high-purity copper and aluminium," Philosophical Magazine A, vol. 82, no. 10, pp. 20712080, 2002.

[20] Y. Liu, S. Varghese, J. Ma, M. Yoshino, H. Lu, and R. Komanduri, "Orientation effects in nanoindentation of single crystal copper," International Journal of Plasticity, vol. 24, no. 11, pp. 19902015, 2008.

[21] M. C. Fivel, C. F. Robertson, G. R. Canova, and L. Boulanger, "Three-dimensional modeling of indent-induced plastic zone at a mesoscale," Acta Materialia, vol. 46, no. 17, pp. 6183-6194, 1998.

[22] S.-R. Jian, J.-Y. Juang, C.-W. Luo, S.-A. Ku, and K.-H. Wu, "Nanomechanical properties of GaSe thin films deposited on $\mathrm{Si}\left(\begin{array}{l}1 \\ 1\end{array} 1\right)$ substrates by pulsed laser deposition," Journal of Alloys and Compounds, vol. 542, pp. 124-127, 2012.

[23] W. C. Oliver and G. M. Pharr, "Improved technique for determining hardness and elastic modulus using load and displacement sensing indentation experiments," Journal of Materials Research, vol. 7, no. 6, pp. 1564-1580, 1992.

[24] G. M. Pharr, W. C. Oliver, and F. R. Brotzen, "On the generality of the relationship among contact stiffness, contact area, and elastic modulus during indentation," Journal of Materials Research, vol. 7, no. 3, pp. 613-617, 1992.

[25] N. Janakiraman and F. Aldinger, "Indentation analysis of elastic and plastic deformation of precursor-derived Si-C-N ceramics," Journal of the European Ceramic Society, vol. 30, no. 3, pp. 775$785,2010$.

[26] R. B. King, "Elastic analysis of some punch problems for a layered medium," International Journal of Solids and Structures, vol. 23, no. 12, pp. 1657-1664, 1987.

[27] M. He, F. Li, J. Cai, and B. Chen, "An indentation technique for estimating the energy density as fracture toughness with 
Berkovich indenter for ductile bulk materials," Theoretical and Applied Fracture Mechanics, vol. 56, no. 2, pp. 104-111, 2011.

[28] J. Li, F. Li, M. He, F. Xue, M. Zhang, and C. Wang, "Indentation technique for estimating the fracture toughness of 7050 aluminum alloy with the Berkovich indenter," Materials and Design, vol. 40, pp. 176-184, 2012.

[29] Y.-T. Cheng and C.-M. Cheng, "Relationships between hardness, elastic modulus, and the work of indentation," Applied Physics Letters, vol. 73, no. 5, pp. 614-616, 1998.

[30] Y.-T. Cheng and C.-M. Cheng, "Scaling approach to conical indentation in elastic-plastic solids with work hardening," Journal of Applied Physics, vol. 84, no. 3, pp. 1284-1291, 1998.

[31] Y.-T. Cheng and C.-M. Cheng, "Can stress-strain relationships be obtained from indentation curves using conical and pyramidal indenters?" Journal of Materials Research, vol. 14, no. 9, pp. 3493-3496, 1999.

[32] Y.-T. Cheng and C.-M. Cheng, "Relationships between initial unloading slope, contact depth, and mechanical properties for conical indentation in linear viscoelastic solids," Journal of Materials Research, vol. 20, no. 4, pp. 1046-1053, 2005.

[33] K. Tunvisut, N. P. O'Dowd, and E. P. Busso, "Use of scaling functions to determine mechanical properties of thin coatings from microindentation tests," International Journal of Solids and Structures, vol. 38, no. 2, pp. 335-351, 2001.

[34] M. Dao, N. Chollacoop, K. J. van Vliet, T. A. Venkatesh, and S. Suresh, "Computational modeling of the forward and reverse problems in instrumented sharp indentation," Acta Materialia, vol. 49, no. 19, pp. 3899-3918, 2001.

[35] J.-Y. Kim, K.-W. Lee, J.-S. Lee, and D. Kwon, "Determination of tensile properties by instrumented indentation technique: representative stress and strain approach," Surface and Coatings Technology, vol. 201, no. 7, pp. 4278-4283, 2006.

[36] X.-L. Gao, "New expanding cavity model for indentation hardness including strain-hardening and indentation size effects," Journal of Materials Research, vol. 21, no. 5, pp. 1317-1326, 2006.

[37] H. Yuan and J. Chen, "Identification of the intrinsic material length in gradient plasticity theory from micro-indentation tests," International Journal of Solids and Structures, vol. 38, no. 46-47, pp. 8171-8187, 2001.

[38] H. Yuan and J. Chen, "The role of intrinsic material length scales in micro-indentation simulations," Computational Materials Science, vol. 25, no. 1-2, pp. 253-263, 2002.

[39] R. K. A. Al-Rub and G. Z. Voyiadjis, "Analytical and experimental determination of the material intrinsic length scale of strain gradient plasticity theory from micro- and nano-indentation experiments," International Journal of Plasticity, vol. 20, no. 6, pp. 1139-1182, 2004.

[40] R. K. Abu Al-Rub and G. Voyiadjis, "Determination of the material intrinsic length scale of gradient plasticity theory," International Journal for Multiscale Computational Engineering, vol. 2, no. 3, 24 pages, 2004.

[41] G. Z. Voyiadjis and R. A. Al-Rub, "Determination of the material intrinsic length scale of gradient plasticity theory," in IUTAM Symposium on Multiscale Modeling and Characterization of Elastic-Inelastic Behavior of Engineering Materials, vol. 114 of Solid Mechanics and Its Applications, pp. 167-174, Springer, Dordrecht, The Netherlands, 2004.

[42] S. Shim, J.-I. Jang, and G. M. Pharr, "Extraction of flow properties of single-crystal silicon carbide by nanoindentation and finite-element simulation," Acta Materialia, vol. 56, no. 15, pp. 3824-3832, 2008.

[43] W. D. Nix and H. Gao, "Indentation size effects in crystalline materials: a law for strain gradient plasticity," Journal of the Mechanics and Physics of Solids, vol. 46, no. 3, pp. 411-425, 1998.
[44] J. Li, F. Li, M. He, F. Xue, M. Zhang, and C. Wang, "Indentation technique for estimating the fracture toughness of 7050 aluminum alloy with the Berkovich indenter," Materials \& Design, vol. 40, pp. 176-184, 2012.

[45] Z. Yuan, F. Li, P. Zhang, B. Chen, and F. Xue, "Mechanical properties study of particles reinforced aluminum matrix composites by micro-indentation experiments," Chinese Journal of Aeronautics, vol. 27, no. 2, pp. 397-406, 2014.

[46] C. Walter and C. Mitterer, "3D versus 2D finite element simulation of the effect of surface roughness on nanoindentation of hard coatings," Surface and Coatings Technology, vol. 203, no. 20-21, pp. 3286-3290, 2009.

[47] Y. Liu, B. Wang, M. Yoshino, S. Roy, H. Lu, and R. Komanduri, "Combined numerical simulation and nanoindentation for determining mechanical properties of single crystal copper at mesoscale," Journal of the Mechanics and Physics of Solids, vol. 53, no. 12, pp. 2718-2741, 2005.

[48] S.-R. Jian, C.-H. Tasi, S.-Y. Huang, and C.-W. Luo, "Nanoindentation pop-in effects of $\mathrm{Bi}_{2} \mathrm{Te}_{3}$ thermoelectric thin films," Journal of Alloys and Compounds, vol. 622, pp. 601-605, 2015.

[49] J. Cai, F. Li, T. Liu, and B. Chen, "Investigation of mechanical behavior of quenched Ti-6Al-4V alloy by microindentation," Materials Characterization, vol. 62, no. 3, pp. 287-293, 2011.

[50] M. S. Park and Y. S. Suh, "Hardness estimation for pile-up materials by strain gradient plasticity incorporating the geometrically necessary dislocation density," Journal of Mechanical Science and Technology, vol. 27, no. 2, pp. 525-531, 2013.

[51] K. Durst, B. Backes, and M. Göken, "Indentation size effect in metallic materials: correcting for the size of the plastic zone," Scripta Materialia, vol. 52, no. 11, pp. 1093-1097, 2005.

[52] H. Ledbetter and A. Migliori, "A general elastic-anisotropy measure," Journal of Applied Physics, vol. 100, no. 6, Article ID 063516, 2006.

[53] D. Tabor, The Hardness of Metals, Clarendon Press, Oxford, UK, 1951.

[54] J. Dong, F. Li, and C. Wang, "Micromechanical behavior study of $\alpha$ phase with different morphologies of Ti-6Al-4V alloy by microindentation," Materials Science and Engineering: A, vol. 580, pp. 105-113, 2013.

[55] S.-R. Jian and Y.-Y. Lin, "Berkovich nanoindentation-induced dislocation energetics and pop-in effects in ZnSe thin films," Journal of Alloys and Compounds, vol. 590, pp. 153-156, 2014.

[56] C.-H. Tasi, Y.-C. Tseng, S.-R. Jian et al., "Nanomechanical properties of $\mathrm{Bi}_{2} \mathrm{Te}_{3}$ thin films by nanoindentation," Journal of Alloys and Compounds, vol. 619, pp. 834-838, 2015.

[57] S. Mandal, V. Rakesh, P. V. Sivaprasad, S. Venugopal, and K. V. Kasiviswanathan, "Constitutive equations to predict high temperature flow stress in a Ti-modified austenitic stainless steel," Materials Science and Engineering A, vol. 500, no. 1-2, pp. 114-121, 2009.

[58] M. He, F. Li, and N. Ali, "A normalized damage variable for ductile metals based on toughness performance," Materials Science and Engineering A, vol. 528, no. 3, pp. 832-837, 2011.

[59] S. Mandal, P. V. Sivaprasad, S. Venugopal, and K. P. N. Murthy, "Artificial neural network modeling to evaluate and predict the deformation behavior of stainless steel type AISI 304L during hot torsion," Applied Soft Computing Journal, vol. 9, no. 1, pp. 237-244, 2009. 

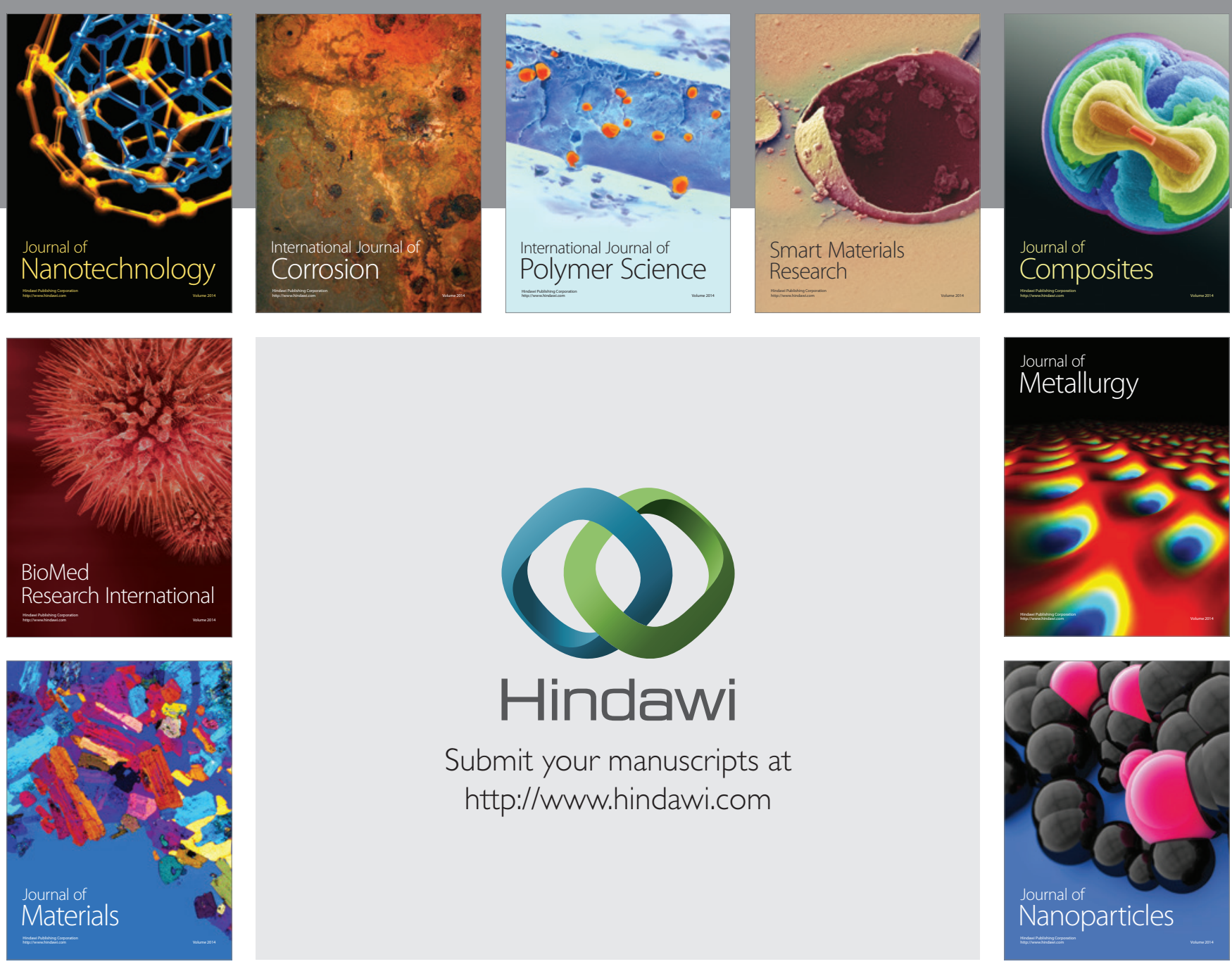

Submit your manuscripts at http://www.hindawi.com
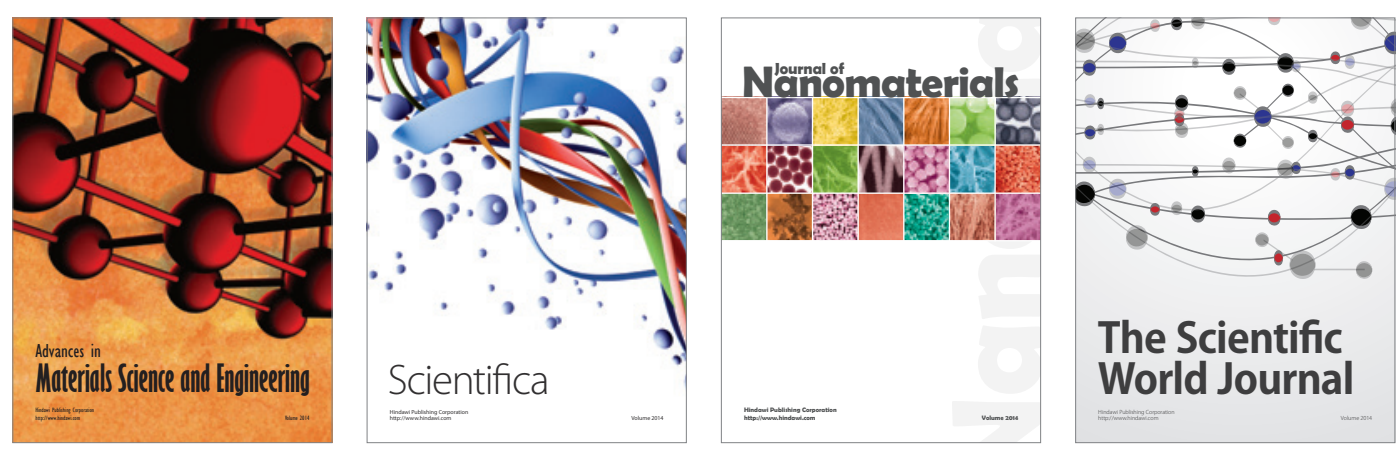

\section{The Scientific World Journal}
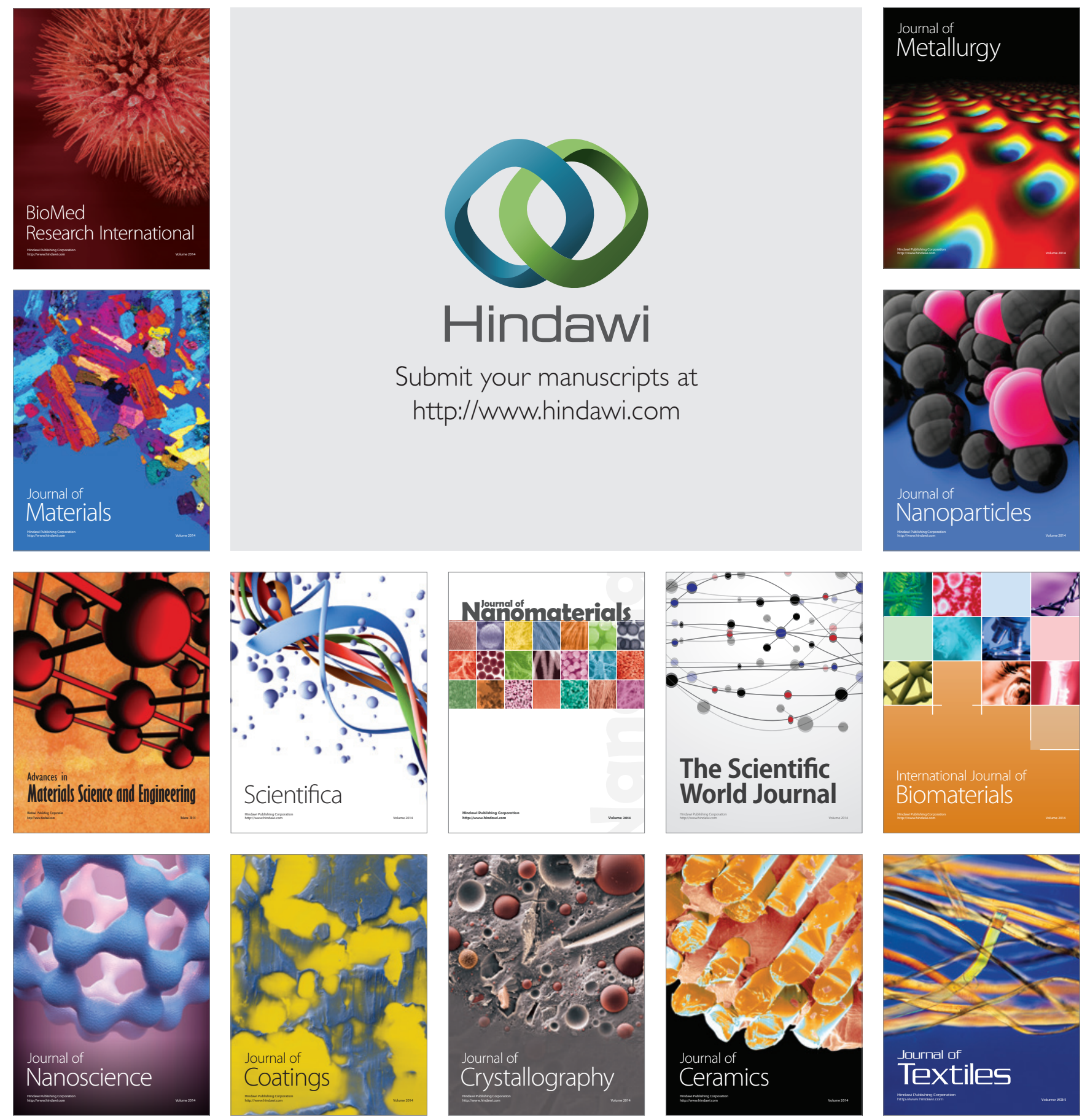